\title{
The anaphase-promoting complex: it's not just for mitosis any more
}

\author{
J. Wade Harper, ${ }^{1,3}$ Janet L. Burton, ${ }^{2}$ and Mark J. Solomon ${ }^{2}$ \\ ${ }^{1}$ Department of Biochemistry and Molecular Biology, Baylor College of Medicine, Houston, Texas 77030, USA; ${ }^{2}$ Department \\ of Molecular Biophysics and Biochemistry, Yale University, New Haven, Connecticut 06520-8024, USA
}

The ability of cells to make exact replicas of themselves is central to the life and development of complex organisms. Initial insights into the question of how cells divide came during the latter half of the 19th century when Walther Flemming visualized structures he called threads (which we now call chromosomes) and described how these threads change during cell multiplication, a process he called mitosis. Now, more than a century later, we have a molecular understanding of many of the cellular processes that Flemming observed. Indeed, major cytological events occurring during mitosis are known to constitute cell cycle transitions and are regulated by complex signal transduction pathways whose major components have been identified during the past decade. In this review, we describe recent efforts to understand how central components of this regulatory apparatus-cyclin-dependent kinases and the anaphasepromoting complex/cyclosome (APC/C) - control progression through the cell division cycle and how regulatory mechanisms impinge on the APC/C. The $\mathrm{APC} / \mathrm{C}$ is the multisubunit ubiquitin ligase whose activity is precisely regulated to ensure the timely degradation of cyclins and other key cell cycle regulators in unperturbed cells and to respond to mitotic checkpoints that prevent their degradation. We pay particular attention to recent developments as excellent reviews are available from a few years ago (Morgan 1999; Zachariae and Nasmyth 1999).

\section{Cell cycle transitions: interplay between}

cyclin-dependent kinases and

ubiquitin-mediated proteolysis

The primary task of the cell division cycle is to duplicate genetic information precisely through the process of DNA replication ( $S$ phase) and then to allocate this information equally to two daughter cells through mitosis. Inaccuracies in this process can be problematic. For example, cells that attempt to separate chromosomes that are incorrectly or incompletely duplicated are much

\footnotetext{
${ }^{3}$ Corresponding author.
}

E-MAIL jharper@bcm.tmc.edu; FAX (713) 796-9438.

Article and publication are at http://www.genesdev.org/cgi/doi/10.1101/ gad.1013102. more likely to incur fatal or irreparable damage as a result of either loss or gain of genetic information. Thus, a large number of signaling pathways collaborate to enforce order on cell division events.

Cell cycle transitions are the primary mechanism used by the cell to establish the order and timing of cell cycle events. Such transitions occur when there is a change in the biochemical status of the cell division machinery. Early cell-fusion experiments showed that major cell cycle phases can be incompatible with one another. For example, when a $G_{2}$ cell is fused with an S-phase cell, the $G_{2}$ nucleus waits until the S-phase nucleus has completed replication before both nuclei enter mitosis synchronously (Rao and Johnson 1970). Thus, progression through $G_{2}$ into mitosis is incompatible with ongoing DNA synthesis. Through subsequent genetic and biochemical analysis, we now understand in general terms how these cell cycle dependencies are generated and controlled. Moreover, molecules that play key roles in defining particular cell cycle stages have been uncovered. One frequently used paradigm involves an inhibitor-activator module; a protein complex in which an activator of a particular transition is held in an inactive form by an inhibitory factor (Fig. 1A). The definition of a specific component as an inhibitor or activator is frequently complicated by the fact that a given protein may perform both roles; an activator of a particular transition may become an inhibitor of a subsequent transition. A case in point is the Cdk inhibitor Sic1 in budding yeast. Sic1 promotes mitotic exit by inhibiting the activity of mitotic cyclin/Cdk complexes (Clb2/Cdc28) but blocks Sphase entry by inhibiting a closely related pair of S-phase Cdk complexes (Clb5-6/Cdc28). As described in more detail below, the mitotic inhibitor Pds1 and B-type cyclins display similar dual functions. Thus, molecules that function as both inhibitors and activators of cell proliferation are frequently nodes of regulation and are used as focal points for the integration of multiple signaling pathways that monitor ongoing and completed cellular events and that link these with transitions.

Ubiquitin-mediated degradation of inhibitory factors is a primary mechanism by which a change in cell cycle state is achieved. This process involves the covalent attachment of ubiquitin chains to lysine residues in a target protein, leading to its recognition and degradation by 


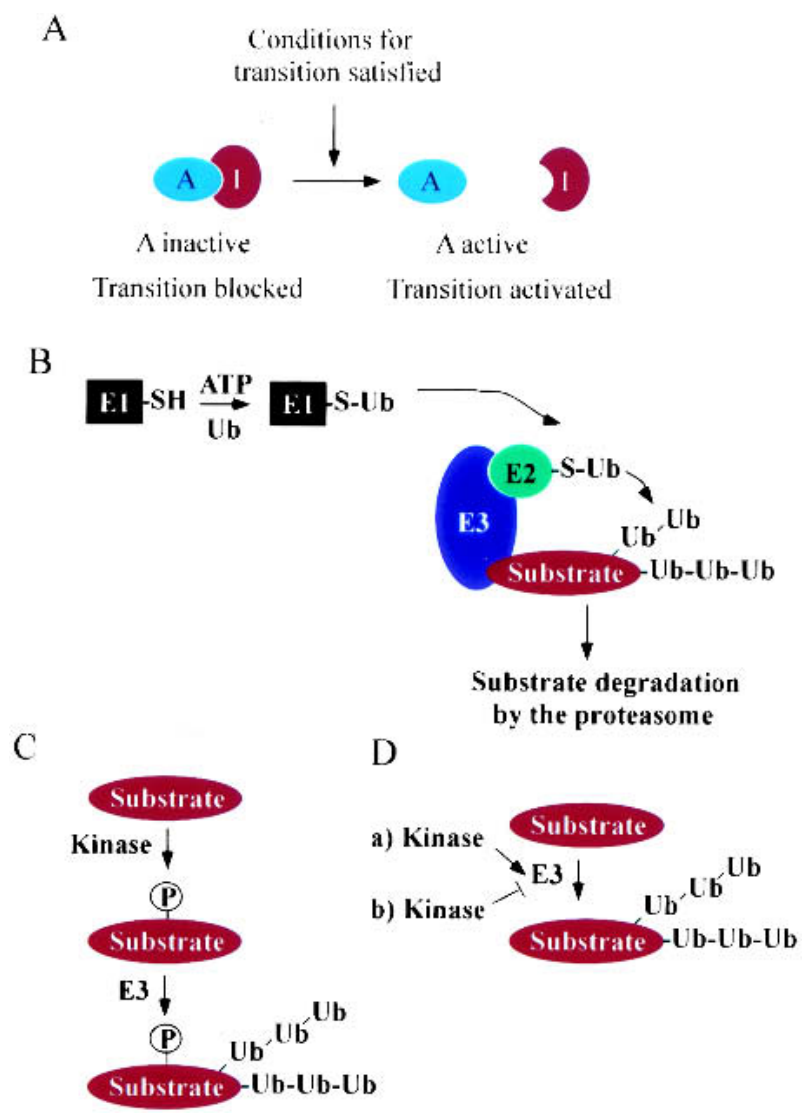

Figure 1. (A) Schematic representation of a common mechanism used to control cell cycle transitions. When an activating component $\mathrm{A}$ is associated with an inhibitory component $\mathrm{I}$, the cell cycle transition is blocked. In response to appropriate signals, association of A with I is abolished (in some cases through proteolytic destruction of I) and A can activate the transition. In some cases, I has served a positive role in a previous step in the cell cycle. (B) Degradation of protein substrates through the ubiquitin-proteasome pathway involves three components, E1, E2, and E3. E1 uses ATP to form a high-energy thiol ester with the C-terminal glycine of ubiquitin. This ubiquitin is then transferred to a cysteine residue in one of several E2s. Specific E2s assemble with appropriate E3s to initiate transfer of ubiquitin to an associated substrate. Multiple rounds of ubiquitination of the initial ubiquitin conjugate lead to the formation of polyubiquitin chains, which are then recognized by the proteasome, which degrades the ubiquitinated protein. $(C, D)$ Regulation of ubiquitination can occur through multiple mechanisms. Some ubiquitination reactions $(C)$, such as those involving known SCF-mediated pathways, require that the substrate be phosphorylated to be recognized by the E3. In other cases such as the $\operatorname{APC}(D)$, the E3 is the target of regulation by phosphorylation, and substrate recognition does not require that the substrate be phosphorylated. With the APC $(D)$, phosphorylation can either act to positively (pathway a) or negatively (pathway b) regulate activity, depending on the context.

the proteasome. The specificity of ubiquitin-mediated proteolysis is exquisite, allowing a single protein within a larger complex to be modified and destroyed. Moreover, the fact that ubiquitin-mediated proteolysis is both rapid and irreversible means that the change in cell cycle state can occur in a unidirectional switch-like fashion. Ubiquitination involves three major steps (Fig. 1B; Hershko and Ciechanover 1998). First, the ubiquitin-activating enzyme E1 uses ATP to generate a thiol ester between its active-site cysteine and the C-terminal glycine residue of ubiquitin. Second, the ubiquitin is transferred to the active-site cysteine of an E2 (ubiquitin-conjugating enzyme). Third, the E2 assembles with an E3 (ubiquitin ligase) and then transfers ubiquitin to one or more lysine residues of a substrate protein to generate a stable isopeptide linkage. Multiple rounds of ubiquitin transfer to the initial ubiquitin conjugate lead to the formation of polyubiquitin chains, which are then recognized by the regulatory cap of the proteasome. E3s are key components of ubiquitination pathways because they determine the substrate specificity of ubiquitination reactions, they recruit the appropriate $\mathrm{E} 2$, and they may also contribute to E2 activity.

Because the degradation of key cell cycle regulators typically occurs in response to the fulfillment of multiple criteria, it is not surprising that complex signaling systems impinge on key ubiquitination reactions. Many of these signaling systems involve input from a protein kinase pathway and can act either positively or negatively. In some cases, the substrate itself is the recipient of regulatory information, and its phosphorylation sets up the timing of its ubiquitination. For example, many substrates of the SCF (Skp1/Cul1/F-box protein) ubiquitin ligase need to be phosphorylated prior to binding to the SCF, which can be constitutively active (for review, see Deshaies 1999; Koepp et al. 1999). In other cases, such as the APC/C, protein kinases affect primarily the activity status of the E3 in either positive or negative ways (for review, see Morgan 1999; Zachariae and Nasmyth 1999). Of course, variations on these themes exist, including the use of coactivators and inhibitory subunits.

\section{Cycling into destruction: discovery of the APC/C}

The APC/C and SCF ubiquitin ligases have emerged from studies aimed at understanding how key components of the cell cycle-cyclins and cyclin-dependent kinase inhibitors-are regulated. An unexpected surprise was that the discovery of these ligases provided not only the key to understanding how Cdk activity is regulated but also insights into how other basic processes such as sister-chromatid separation are controlled, and how numerous phosphorylation-driven signaling pathways are regulated.

Initial insight into the problem of regulated proteolysis of cell cycle molecules came from an attempt to understand how mitotic cyclins are degraded as cells pass through mitosis (for review, see Zachariae and Nasmyth 1999). Multiple systems contributed to developments in this area, but experiments in clam, sea urchin, and Xenopus egg extracts were crucial in framing the problem. Cyclins A and B were identified in marine invertebrates as proteins that are translated in response to fertilization but rapidly degraded at each cleavage of the early em- 
bryo, suggesting that this disappearance was cell cycle regulated (Evans et al. 1983). Efforts to link A- and B-type cyclins with maturation promoting factor, an activity required for the interphase-to-metaphase transition, and with the Cdc2 protein kinase simultaneously led to the finding that cyclin B alone is sufficient to induce mitosis in interphase egg extracts and that cyclin B degradation occurs precisely as cells exit mitosis (Luca and Ruderman 1989; Murray and Kirschner 1989; Murray et al. 1989|. These early experiments also revealed that cyclin $B$ degradation could be triggered in interphase by addition of active Cdc2 (foreshadowing the role of Cdk-mediated APC/C phosphorylation in its activation) and that cyclin $\mathrm{B}$ degradation required elements in its $\mathrm{N}$ terminus (foreshadowing the elucidation of a motif, the "destruction box," that serves as a recognition element for the APC/C; Murray et al. 1989; Félix et al. 1990). In fact, the first suggestion that cyclin $\mathrm{B}$ degradation was required for exit from mitosis came from the finding that sea urchin cyclin B $\Delta 90$ (lacking its N-terminal 90 amino acids) could activate Cdc2 and induce mitotic entry but that it was stable and prevented mitotic exit (Murray et al. 1989).

Efforts to elucidate the mechanism underlying cyclin $\mathrm{B}$ degradation led to the finding that cyclin B undergoes covalent modification to form a ladder of proteins with reduced electrophoretic mobility in mitotic extracts but not in interphase extracts (Glotzer et al. 1991). The spacing between these modified forms $(\sim 7 \mathrm{kD})$ suggested that ubiquitin might be involved. At the time, E1 and E2 components had begun to be defined, but a major gap in the ubiquitination field concerned the nature and identity of E3s. Moreover, actual in vivo substrates of the ubiquitin-proteasome system were poorly defined. Thus, cyclin B became an important model system for defining E3s and for understanding how ubiquitin-mediated proteolysis controlled cell cycle transitions, ultimately revealing that the E3 activity required for cyclin $\mathrm{B}$ degradation is also used to destroy other important mitotic regulators.

Initial insight into the cyclin B ubiquitin ligase came from its partial purification from marine invertebrates and Xenopus. Reconstitution of cyclin B ubiquitination activity from fractionated extracts required E1, an E2 activity, and an E3 activity that had the properties of a large complex, with an estimated size of $1500 \mathrm{kD}$ (20S; Hershko et al. 1994; King et al. 1995; Sudakin et al. 1995). The identification of components of the E3 was advanced by the observation that B-type cyclins are not only unstable during mitotic exit but also for an extended period in $G_{1}$ in budding yeast (Amon et al. 1994). This instability during $G_{1}$ facilitated the development of a genetic screen that allowed the identification of several genes, including CDC16 and CDC23, which, when mutated, blocked mitotic cyclin degradation during $G_{1}$ (Irniger et al. 1995). Cdc16 and Cdc23 contain a repetitive protein-protein interaction domain, the TPR motif, but this provided few clues as to how these proteins promoted B-type cyclin degradation. Furthermore, extracts from $c d c 16$ and cdc23 cells (as well as two additional mitotic-arrest mutants, $c d c 26$ and $c d c 27)$ were defective in cyclin ubiquitination, as expected if these proteins were part of an E3 (Zachariae and Nasmyth 1996). Importantly, cdc16 and cdc23 mutants are not only defective in exit from mitosis but are also defective for separation of sister chromatids at the metaphase-to-anaphase transition. These findings provided genetic evidence that the machinery used for cyclin degradation is also involved in other aspects of mitosis (Irniger et al. 1995; for review, see Nasmyth 1999), an idea that was previously proposed based on the finding that the proteasome, but not cyclin B destruction, is required for anaphase in Xenopus extracts (Holloway et al. 1993). The availability of antibodies to human Cdc16 and Cdc27 made it possible to show directly that these proteins are present in purified APC/C complexes from human cells and Xenopus egg extracts, and also made it possible to show that anti-Cdc27 immune complexes contain cyclin-B E3 activity (King et al. 1995). The identification of essential APC/C components not only provided the building blocks with which to define the complex in greater detail (see below) but also, together with the identification of APC/C-targeting sequences, the Destruction and KEN boxes, facilitated the identification of APC/C substrates other than mitotic cyclins.

\section{APC/C composition and structure: relationship with the SCF ubiquitin ligase}

The large size of the purified cyclin-B E3 suggested that components in addition to Cdc16 and Cdc23 would be present. These components were identified biochemically from both yeast and Xenopus, and the corresponding human cDNAs were identified (Table 1; Peters et al. 1996; Zachariae et al. 1996, 1998b; Yu et al. 1998). Several APC/C components were also identified in a collection of cut mutants in Schizosaccharomyces pombe (Yamashita et al. 1999; Tatebe and Yanagida 2000). Budding yeast APC/C contains 11 core subunits that remain tightly associated throughout purification and are all required for timely mitosis. Like the TPR-repeat-containing subunits, temperature-sensitive mutations in APC1, $A P C 2$, and $A P C 11$ arrest in metaphase at the nonpermissive temperature because of an inability to induce loss of sister-chromatid cohesion (Zachariae et al. 1996, 1998b; K.M. Kramer et al. 1998). These mutants are also defective in B-type cyclin degradation in vivo and cyclin B ubiquitination in extracts (Zachariae et al. 1998b). Apc9, although not essential for viability, is nevertheless required for efficient entry into anaphase. Doc1 was originally identified in budding yeast (Hwang and Murray 1997) and later found as a component of the human and S. pombe APC/C, referred to as APC10 (Kominami et al. 1998; Grossberger et al. 1999; Kurasawa and Todokoro 1999). Doc1 is required for Clb2 degradation during mitotic exit in budding yeast. Although a role for Doc1 in early mitotic events has not been reported, a radiationinduced mouse mutant called oligosyndactylism displays defects in the metaphase-to-anaphase transition. This mutation appears to inactivate the APC10/Doc1 gene (Pravtcheva and Wise 2001). Detailed analyses of 
Harper et al.

Table 1. APC subunits

\begin{tabular}{|c|c|c|c|c|c|c|}
\hline $\begin{array}{l}\text { Saccharomyces } \\
\text { ceravisiae }\end{array}$ & $\begin{array}{c}\text { Schizosaccharomyces } \\
\text { pombe }\end{array}$ & Homo sapien & $\begin{array}{l}\text { Drosophila } \\
\text { melanogaster }\end{array}$ & Caenorhabditis elegans & Function & Motifs \\
\hline Apc1 & Cut4 & tsg24/Apc1 & CG9198 & mat-2, pod-3, W10C6.1 & & $\mathrm{Rpn} 1 / 2$ \\
\hline Apc2 & SPBP23A10.04 & Apc2 & CG3060 & K06H7.6 & $\begin{array}{l}\text { Scaffold, binds Apc2 } \\
\text { and Ubcs }\end{array}$ & $\begin{array}{l}\text { Cullin homology } \\
\text { domain }\end{array}$ \\
\hline $\mathrm{Cdc} 27$ & Nuc2 & Cdc27/Apc3 & $c d c 27$ & mat-1, pod-5, CE23241 & & $\begin{array}{l}\text { TPR repeats, Cdk } \\
\text { phospharylation }\end{array}$ \\
\hline Apc4 & Cut20, Lid1 & Apc4 & CG4350 & & & \\
\hline Apc5 & Apc5, spac959, 09C & Apc5 & CG10850/ida & M163.4 & & \\
\hline Cdc16 & Cut 9 & Cdc16/Apc6 & $c d c 16$ & pod-6, emb-27, F10B5.6 & & $\begin{array}{l}\text { TPR repeats, Cdk } \\
\text { phosphorylation }\end{array}$ \\
\hline $\operatorname{Cdc} 26$ & Hen1 & $\mathrm{Cdc} 26$ & & & & \\
\hline $\mathrm{Cdc} 23$ & Cut23 & Cdc23/Apc8 & CG2508 & mat-3, F10C5.1 & & $\begin{array}{l}\text { TPR repeats, Cdk } \\
\text { phosphorylation }\end{array}$ \\
\hline Apc9 & & & & & & $\begin{array}{l}\text { Nonessential for } \\
\text { viability but } \\
\text { required for timely } \\
\text { anaphase entry }\end{array}$ \\
\hline Doc1 & Apc10 & Apc10 & CG11419 & F15H10.3 & & Doc domain \\
\hline Apc11 & Apc11, SPAC343.03 & Apc11 & lmg (lemming) & F35G12.9 & Recognition of Ubcs & Ring-H2 finger \\
\hline $\operatorname{Cdc} 20$ & Slp1 & $\mathrm{Cdc} 20$ & fzy & cdc20, ZK177.6 & $\begin{array}{l}\text { APC activator/ } \\
\text { specificity factor }\end{array}$ & WD40 repeats \\
\hline Cdh1/Hct1 & Ste9 & Cdh 1 & fzr, rap & fzr, ZK1307.6 & $\begin{array}{l}\text { APC activator/ } \\
\text { specificity factor }\end{array}$ & $\begin{array}{l}\text { WD40 repeats, Cdk } \\
\text { phosphorylation sites }\end{array}$ \\
\hline \multirow[t]{2}{*}{ Amal } & Mfrl & & & & $\begin{array}{l}\text { Meiosis specific APC } \\
\text { activator }\end{array}$ & WD40 repeats \\
\hline & & Apc7 & CG14444 & B0464.2 & & TPR repeats \\
\hline
\end{tabular}

Apc4 and Apc5 mutants have not been reported in budding yeast. However, APC5/ida mutants in Drosophila and APC4/emb-30 mutants in Caenorhabditis elegans produce metaphase arrests (Furuta et al. 2000; Bentley et al. 2002). At present, Apc9 appears to be unique to the budding yeast APC/C (Zachariae et al. 1998b), whereas Apc7 has only been found in metazoans (Table 1; Yu et al. 1998). It is possible that additional APC/C subunits exist, as a small number of proteins in APC/C immune complexes from yeast have not yet been identified (Zachariae et al. 1998b).

The SCF ubiquitin ligase and its role in Cdk regulation

The majority of APC/C subunits have, as yet, unknown functions and in many cases lack conserved domains that would suggest a function. Major exceptions to this generalization are the Apc2 and Apc11 subunits, which display sequence identity with core components of the SCF ubiquitin ligase (Fig. 2A; Yu et al. 1998; Zachariae et al. 1998b). SCF complexes are modular E3s that contain a core ubiquitin ligase composed of Cul1/Cdc53, Skp1, the ring finger protein $\mathrm{Rbx} 1 / \mathrm{Roc} 1 / \mathrm{Hrt} 1$, and a member of the F-box family of proteins, which serves as the substrate receptor (Fig. 2A; Bai et al. 1996; Feldman et al. 1997; Skowyra et al. 1997). The SCF ubiquitin ligase was discovered during efforts to identify the mechanism of degradation of the Sicl Cdk inhibitor and $G_{1}$ cyclins in budding yeast, but it is now recognized as one of the largest families of ubiquitin ligases in eukaryotes (for review, see Patton et al. 1998; Deshaies 1999; Koepp et al. 1999). Initial insight into Sicl turnover came from an analysis of temperature-sensitive yeast mutants that blocked DNA replication but not budding or spindlepole-body duplication. At the nonpermissive temperature, cdc53, cdc4, skp1, and cdc34 strains arrest in $\mathrm{G}_{1}$ with elevated levels of Sic1 and reduced Clb5/Cdc28 activity, whereas analogous mutant cells also lacking Sic1 proceed through S phase and arrest in mitosis (Schwob et al. 1994; Bai et al. 1996). This suggests a role for $\mathrm{SCF}^{\mathrm{Cdc} 4}$ in mitosis, but the nature of this role and the substrates of this E3 during mitosis have yet to be identified.

Although the fact that CDC34 encodes a ubiquitinconjugating enzyme suggested a role for ubiquitin-mediated proteolysis in Sicl regulation (Schwob et al. 1994), it was unclear how these genetically defined components cooperated to regulate Sic1 turnover. The finding that CDC34 and CDC53 were also genetically required for degradation of $\mathrm{G}_{1}$ cyclins (Tyers et al. 1992; Deshaies et al. 1995; Lanker et al. 1996; Mathias et al. 1996; Willems et al. 1996) suggested that these components functioned in multiple proteolysis pathways, but it was not clear how different substrates would be targeted or recognized. The identification of Skp1 as a high-copy suppressor of cdc4 mutants (Bai et al. 1996) provided an answer to this question. Like $c d c 53$ and $c d c 34$ mutants, skp1 mutants display defects in both Sicl and $\mathrm{G}_{1}$ cyclin turnover. Moreover, Skp1 was found to interact with a 40-aminoacid domain in Cdc4 called the F-box, which was also found in a number of other proteins (Bai et al. 1996). One of these proteins, Grr1, had been implicated in turnover of $G_{1}$ cyclins (Barral et al. 1995). This, together with genetic interactions among SKP1,CDC53, and CDC34, led to the idea that these proteins function together with different F-box proteins to direct the ubiquitination of different targets (Bai et al. 1996). This prediction proved correct as reconstituted $\mathrm{SCF}^{\mathrm{Cdc} 4}$ complexes can direct 
A

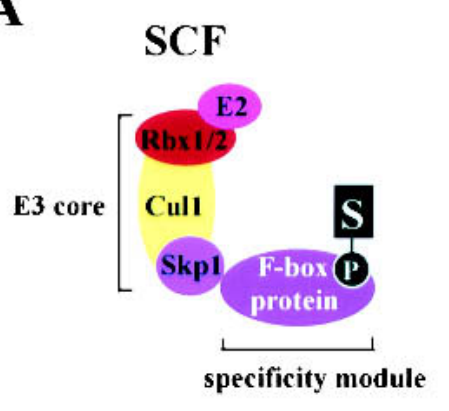

B

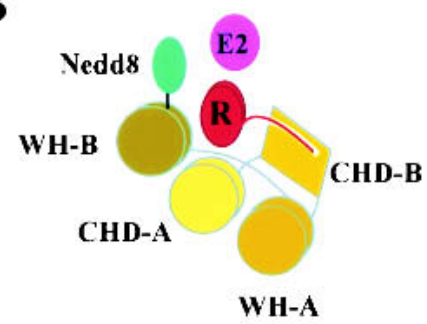

CBC

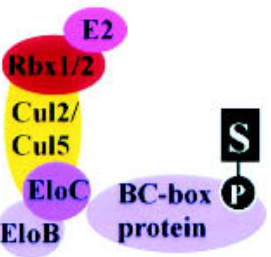

APC Cdc20

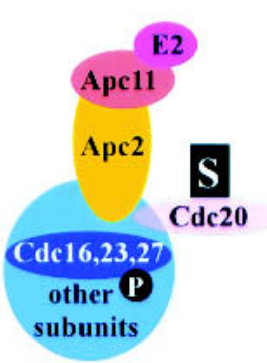

APC Cdh 1
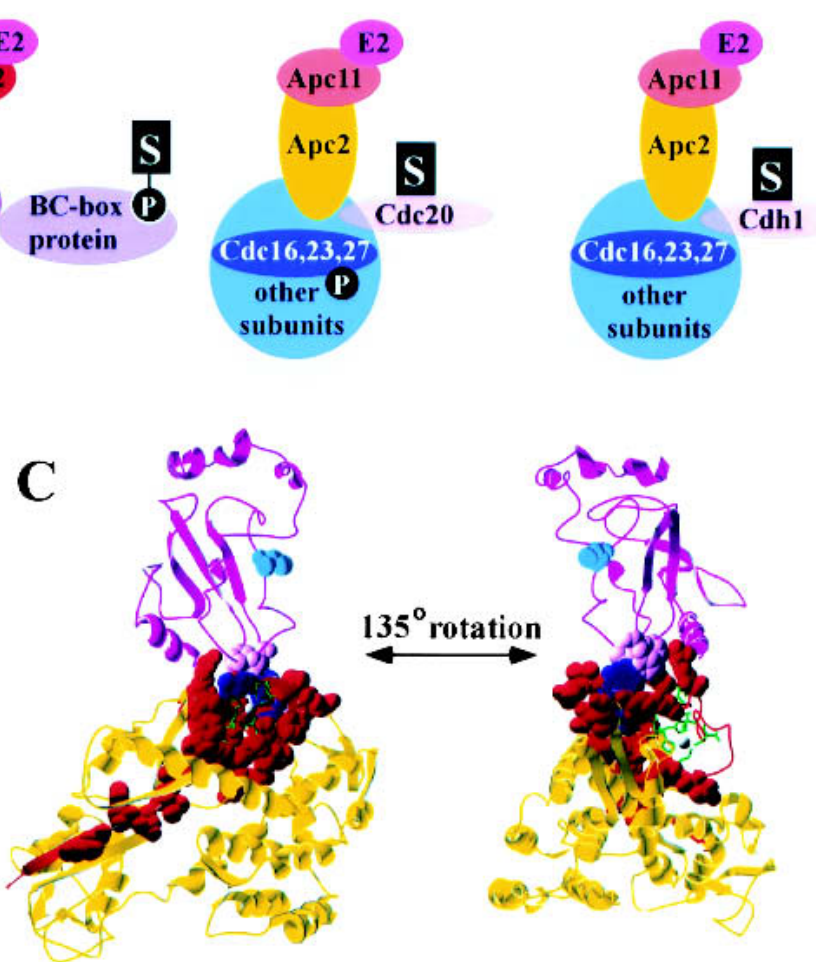

Figure 2. (A) Domain structures of SCF, CBC, and APC/C complexes. All three types of E3s contain a core ubiquitin ligase composed of a cullin-homology domain (CHD) containing protein (yellow), a RING-H2 protein (red/orange), and an adapter such as Skp1 (purple; unknown in the case of the APC/C) to facilitate interaction with substrate receptors (F-box proteins, BC-box proteins, and Cdc20/Cdh1 proteins). The RING-H2 finger assembles with the E2. The contacts made between various APC/C subunits are not known. (B) Schematic representation of the CHD of the SCF complex emphasizing the subdomains that form the cavity where the RING-H2 protein Rbx1 binds (red; see text for details). (C) Conservation between Apc11 and Rbx1. The structure of an Rbx1/Cul1/CHD)/Ubc7 complex was used to display the conservation between Apc11 and Rbx1. The CHD is shown in yellow, Rbx1 in red, and Ubc7 in magenta. Residues conserved in APC11 and Rbx1 are shown in red spacefill. Residues in spacefill blue correspond to those that are conserved in Apc11 and Rbx1 and that are thought to interact with the E2 (Trp 87, Pro 95, Leu 96 in Rbx1). Residues in Ubc7 that are thought to contact the ring domain of Rbx1 are shown in magenta spacefill (Pro 62, Phe 63, Pro 97). The active-site cysteine of Ubc7 is shown in cyan.

the ubiquitination of Sicl, which interacts with the WD40 repeats in the $\mathrm{C}$ terminus of $\mathrm{Cdc} 4$ in a phosphorylation-dependent manner (Feldman et al. 1997; Skowyra et al. 1997), whereas $\mathrm{SCF}^{\mathrm{Grr} 1}$ complexes can promote the ubiquitination of $\mathrm{G}_{1}$ cyclins (Seol et al. 1999; Skowyra et al. 1999), which bind to leucine-rich repeats in Grrl in a phosphorylation-dependent manner (Skowyra et al. 1997; Hsiung et al. 2001).

SCF-mediated ubiquitination is used to control the flux through multiple signaling pathways, including transcriptional control pathways, developmental pathways, and hormone signaling pathways in plants. In all the cases analyzed thus far, protein turnover through the SCF pathways depends on phosphorylation of the substrate, allowing it to interact with the appropriate F-box protein (Deshaies 1999; Koepp et al. 1999). Recent data indicate that turnover of Sicl is ultrasensitive to $\mathrm{Cln} /$ Cdc28 concentrations (Nash et al. 2001), providing a mechanism to link the timing of $\mathrm{Clb} / \mathrm{Cdc} 28$ activation with $\mathrm{G}_{1}$ cyclin levels and nutrients. An ultrasensitive response occurs when a system responds to a graded input with an output that is switch-like or "all-or-none." Ultrasensitivity in the case of Sic1 destruction arises because multiple phosphorylation events are required to allow it to engage SCF ${ }^{\mathrm{Cdc} 4}$. Sic1 contains nine Cdk phosphorylation sites, and at least six of these need to be phosphorylated for efficient recognition by $\mathrm{SCF}^{\mathrm{Cdc} 4}$ (Verma et al. 1997; Nash et al. 2001). Assuming that Cdc28-mediated phosphorylation of Sic1 occurs via a dissociative mechanism, this is expected to generate an ultrasensitive response with a Hill coefficient $>6$ (Nash et al. 2001). The Hill coefficient could actually be much larger owing to positive feedback via Clb5/Cdc28 activity upon Sicl destruction (for review, see Deshaies and Ferrell 2001; Harper 2002). Interestingly, none of the individual phosphorylation sites in Sicl conform to the optimal phospho-peptide recognition motif for Cdc4, but replacing a single phosphorylation site with an optimal 
$\mathrm{Cdc} 4$ recognition sequence in an otherwise nonphosphorylatable Sic1 protein makes the modified Sic1 more unstable than wild-type Sicl (Nash et al. 2001). This change leads to defects in $\mathrm{G}_{1} / \mathrm{S}$ control in vivo and suggests that the use of suboptimal sites and the resulting ultrasensitivity provide a mechanism to tightly link Sic1 turnover to the level of $\mathrm{Cln} / \mathrm{Cdc} 28$ activity. Other phosphorylation-driven ubiquitination reactions may also be ultrasensitive.

\section{Core components of the SCF and APC/C are structurally related}

There are notable structural similarities between SCF and APC/C subunits (Fig. 2A). The identification of Apc2 revealed that it is related to $\mathrm{Cdc} 53$ in that they both share a 180-residue domain referred to as the cullin homology domain (CHD; Zachariae et al. 1998b; Wirbelauer et al. 2000). This domain is found in six closely related cullin family members in multicellular eukaryotes, in Apc2, and in several other more distantly related proteins. Because Cull had been implicated in binding to the E2 Cdc34 (Feldman et al. 1997; Skowyra et al. 1997), this suggested that Apc2 might also recruit an E2.

A more complete understanding of the relationship between SCF complexes and the APC/C came with the identification of the RING-H2 protein Rbx1/Roc1/Hrt1 as a subunit of the SCFs in both yeast and human cells (Kamura et al. 1999; Ohta et al. 1999; Seol et al. 1999; Skowyra et al. 1999). When the RING-H2 protein Apc11 was initially identified as a component of the APC/C, it was shown to be required for APC/C activity (Zachariae et al. 1998b), but its role in ubiquitination was unknown. The identification of a highly related protein in the SCF immediately suggested that the APC/C and SCF shared mechanistic similarities. Like $A p c 11, R b x 1$ is an essential gene in budding yeast, and extracts from cells containing temperature-sensitive mutations in $R b \times 1$ display defects in ubiquitination of Cln 1 and Sic1. Importantly, Rbx1 interacts directly with Cdc53, and this interaction strongly stimulates the association of Cdc34 with Cdc53. Moreover, Rbx1 interacts with Cdc34 by itself, although this binding is stimulated by Cdc53 (Seol et al. 1999; Skowyra et al. 1999). The consequence of this interaction is the activation of ubiquitin-conjugating enzyme activity. Cdc34 displays weak autoubiquitination activity in vitro, but addition of Cdc53/Rbxl complexes stimulates this activity (Seol et al. 1999; Skowyra et al. 1999). Similarly, human Rbxl/Rocl can greatly stimulate formation of ubiquitin chains in vitro /Ohta et al. 1999). These findings suggested that RING-H2 domains such as those contained in Rbxl function to both recruit and activate E2s. Subsequent studies have shown that Apc2 and Apc11 form a ubiquitin ligase core analogous to the Cul1/Rbx1 module (Fig. 2A) and that this complex has the ability both to bind E2s and to stimulate nonspecific ubiquitination activity (Gmachl et al. 2000; Leverson et al. 2000; Tang et al. 2001a). Mutation of the conserved ring-finger domain within Apc11 abolishes this activity.
The cullin/RING-H2 ubiquitin ligase core

Structural studies of SCF complexes and another RING$\mathrm{H} 2$ ubiquitin ligase, $\mathrm{Cbl}$, have helped define how the cullin/RING-H2 modules function in ubiquitination reactions (Zheng et al. 2000, 2002). Cull is a highly elongated protein composed of an $\mathrm{N}$-terminal domain of three repetitive $\alpha$-helical bundles. The extreme $\mathrm{N}$-terminal bundle interacts with Skp1. The C-terminal region contains the CHD and additional sequences that interact with $\mathrm{Rbx} 1$ to form a globular structure composed of a 5 -strand $\beta$-sheet and three independently folded helical bundles (Fig. 2B; Zheng et al. 2002). The previously defined cullin homology domain is composed of a 4-helix bundle linked to an $\alpha / \beta$-domain in which the second strand of the $\beta$-sheet is provided by an extended $\mathrm{N}$ terminus of Rbx1 (residues 20-35). This $\beta$-sheet interaction constitutes all of the interactions between Rbxl and the previously defined CHD and explains the sequence conservation in this domain. One unexpected outcome of this structural analysis is the expansion of the CHD. The C-terminal 180 residues of the CHD contain two winged-helix $(\mathrm{WH})$ domains. The second $\mathrm{WH}$ domain (WH-B) is highly conserved in cullin family members; it forms a cradle that interacts with the RING-H2 domain of $\mathrm{Rbx} 1$ and also contains the conserved lysine residue that is the site of modification by Nedd8 (Fig. 2B), a small 76-residue protein with sequence similarity to ubiquitin. Nedd8's molecular function is unknown, and members of the cullin family of proteins are the only known recipients of Nedd8 conjugation (Tanaka et al. 1998), although more are likely to be found in the future. Linkage of Nedd8 to Cull is required for full catalytic activity of SCF complexes (for review, see Deshaies 1999), and the juxtaposition of the Nedd 8 modification site with the site of Rbx1 binding is presumably of functional importance. Apc2 is not neddylated and displays little sequence identity with cullins in this C-terminal region. Nevertheless, crystallographic analysis has revealed that the $\mathrm{C}$ terminus of Apc2 also forms a WH domain very similar to that found in Cull (Zheng et al. 2002). Overall, these results indicate that the boundaries previously used to define the cullin homology domain should be expanded to include the extreme $\mathrm{C}$ termini of cullin and Apc2 family members. Based on the Rbx1/Cull structure, it is expected that Apc11 will interact with the C-terminal WH domain of Apc2, and one could speculate that other APC/C subunits might play a role analogous to that played by Nedd8 in cullin complexes.

A major question concerns how E2s are recruited to and recognized by the APC/C. Previous studies have shown that the APC/C can use multiple E2 family members, including human $\mathrm{UbcH} 10$ and its close homologs UbcX and E2-C (Aristarkhov et al. 1996; Yu et al. 1996; Osaka et al. 1997; Townsley et al. 1997), as well as Ubc4 from yeast (Charles et al. 1998). However, the APC/C is apparently unable to use Ubc3/Cdc34, a major SCF E2. Structural information relevant to E2 selection by RING-H2-based E3s has come from the analysis of Cbl, a ring-finger protein involved in receptor tyrosine kinase 
turnover, in complexes with UbcH7 (Zheng et al. 2000). Highly conserved Phe and Pro residues in UbcH7 interact with a hydrophobic surface in the $\mathrm{Cbl}$ ring-finger domain, which is formed primarily by the canonical RING-H2 domain. Key residues in Cbl involved in interaction with UbcH7 (Trp 87, Pro 95, Leu 96) are all conserved in Rbxl, suggesting that Rbxl will interact in a similar way with Ubc3/Cdc34. Consistent with the involvement of these residues, mutation of Trp 87 in Rbx1 leads to a nonfunctional protein (Zheng et al. 2002). Interestingly, Apc11 and Rbx1 are quite similar in this region (Fig. 2C). Although structural studies are necessary to determine precisely how E2s interact with Rbx1/Cul1 and Apc11/Apc2 complexes, the available data suggest a generally conserved mechanism for interactions between E2s and distantly related RING-H2 domains. However, it is unclear at present what dictates the specificity of interaction of E2s with various RING-H2 proteins. In addition, Ubc4 interacts with Apc11 and most likely the Apc11/Apc2 complex, whereas UbcH10 does not require coexpressed Apc11 to interact with Apc2 (Tang et al. 2001a). Precisely how the Apc2/UbcH10 interaction occurs and whether it contributes to ubiquitination is unclear.

\section{Structural analysis of the $A P C / C$}

Although we are now beginning to understand how the cullin-RING-H2 modules of the APC/C function in ubiquitination, we have little mechanistic information concerning other APC/C subunits. In principle, these subunits could be involved in binding to the APC/C activators $\mathrm{Cdc} 20$ and $\mathrm{Cdh} 1$ or in localizing the APC/C to particular structures in the cell. Alternatively, some of these subunits, such as Cdc16, Cdc23, and Cdc27, which are phosphorylated (see below), could be used as recipients of regulatory information. A complete understanding of APC/C function will require structural analysis, but this goal will be a challenge because of the APC/C's complex composition. Recent work has led to a low-

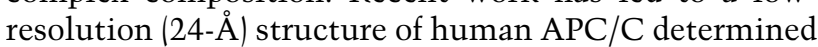
by cryo-electron microscopy and image reconstruction (Gieffers et al. 2001). The structure is dominated by an outer protein wall containing an inner channel that has been hypothesized to be the reaction chamber. It is unclear where critical subunits are in this structure, and additional work is needed to establish the quaternary organization of the individual subunits. One approach will involve structure determination of APC/C subcomplexes and individual subunits, which can then be modeled on low-resolution structures. It has been known for some time that loss of particular subunits such as the nonessential subunits Cdc26 and Apc9 leads to rearrangement of the APC/C (Zachariae et al. 1998b). For example, Apc2 immune complexes from cells lacking Cdc26 contain greatly reduced levels of Cdc16, Cdc27, and Apc9, suggesting that these subunits form a subcomplex.

The only APC/C subunit to be examined crystallographically thus far is Doc1/Apc10, which is the found- ing member of a family of proteins that contain a Doc1 domain. Doc1 domains are not limited to the APC/C. In fact, several Doc1-domain-containing proteins have been identified that also contain other domains implicated in ubiquitination, including the $\mathrm{CHD}$, suggesting that Doc1 domains play a general role in ubiquitination reactions (Grossberger et al. 1999). The Doc1 domain from both yeast (Au et al. 2002) and humans (Wendt et al. 2001) forms a twisted $\beta$-sandwich jelly-roll structure. This structure is quite similar to the fold found in several proteins involved in biomolecular interactions, including galactose oxidase, sialidase, and XRCC1, although this similarity is not evident at the level of primary sequence. Interestingly, conserved residues in Doc1 domains cluster on a single surface of the protein that is analogous to the surface used by sialidase to bind its ligand. Moreover, this patch also contains Ser 148, which is the site of a temperature-sensitive mutation in yeast Doc1 (Hwang and Murray 1997). Taken together, these data suggest that Docl may interact with APC/C components or substrates of the reaction through this conserved domain. Finding proteins that interact with Doc1 may help uncover the function of this subunit and may also aid in understanding the role of Doc1 domains in other classes of E3.

\section{APC/C activators: $C d c 20$ and Cdh1}

Most of the substrate selectivity of the APC/C resides in the so-called activator proteins Cdc20 (also called p55 $5^{\mathrm{CDC}}$ and fizzy, $f z y$ ) and Cdh1 (also called Hct1 and fizzy-related, $f z r)$. The initial characterization of cell cycle mutants in budding yeast showed that cells mutant for CDC20 had a similar arrest phenotype as cells mutant for what subsequently became known as genes for APC/C subunits such as CDC23, CDC26, and $C D C 27$. The first direct connection to cell cycle proteolysis came from Drosophila, where fizzy mutants failed to degrade mitotic cyclins (Dawson et al. 1993; Sigrist et al. 1995). Cdc20 is required for APC/C function in mitosis (see below). Cdh1/Hct1 (Cdc20 homolog/Homolog of Cdc twenty) was first identified in budding yeast and found to be necessary for the activity of the APC/C in late mitosis and in $\mathrm{G}_{1}$ (Schwab et al. 1997; Visintin et al. 1997). Similarly, Drosophila fzr was found to be required for maintaining low mitotic cyclin levels in $\mathrm{G}_{1}$ (Sigrist and Lehner 1997). Cdc20 and Cdh1 are members of a multigene family. For example, a meiosis-specific form, called Ama1, has been found in Saccharomyces cerevisiae (Cooper et al. 2000), and multiple Cdh1 homologs have been found in chickens (Wan and Kirschner 2001; see below). As described below, the use of multiple APC/ $\mathrm{C}$-activating proteins allows flexibility in APC/C function.

Complementing the genetic evidence that $\mathrm{Cdc} 20$ and $\mathrm{Cdh} 1$ are required for APC/C function in vivo, biochemical experiments showed that they were necessary for APC/C activity in vitro (Fang et al. 1998a; E.R. Kramer et al. 1998; Jaspersen et al. 1999). Added Cdh1 was necessary for the activity of the APC/C immunoprecipitated 
from yeast cell extracts (Jaspersen et al. 1999). Similarly, added Cdh1 and Cdc20 were each able to activate immunopurified Xenopus and human APC/C (Fang et al. 1998a; E.R. Kramer et al. 1998). Interestingly, addition of Cdc20 and Cdh1 conferred distinct substrate selectivities on the APC/C. This specificity is reflected in the general tendency of $\mathrm{Cdc} 20$ to target the APC/C to substrates containing a degradation signal called the destruction box and for Cdh1 to target the APC/C to substrates containing a distinct signal termed the KEN box (see below). Although the simplest explanation for the distinct substrate specificities of APC ${ }^{\mathrm{Cdc} 20}$ and APC ${ }^{\mathrm{Cdh} 1}$ would be that $\mathrm{Cdc} 20$ and $\mathrm{Cdh} 1$ recruited substrates to the APC/C, there was no evidence for this until recently. Hence, for some years Cdc20 and Cdh1 were known simply as "APC/C activators" to indicate simultaneously their requirement for $\mathrm{APC} / \mathrm{C}$ function and our ignorance about their biochemical roles. Because they bind to the APC/C and confer substrate specificity upon it, Cdc20 and Cdh1 play the role that F-box proteins play in SCF complexes. However, Cdc20 and Cdh1 only associate with the APC/C transiently, essentially making them alternative substoichiometric APC/C subunits. How these two proteins coordinate distinct cell cycle transitions is discussed below.

\section{Integration of $\mathrm{APC} / \mathrm{C}$ activity with cell cycle transitions}

Research during the last decade has revealed that the chromosome cycle is inextricably linked with the Cdk cycle. There are two major states of Cdk activity during the cell cycle; a state where Cdk activity is high and a state where Cdk activity is low (Fig. 3A; Amon 1997; Irniger and Nasmyth 1997). This periodicity underlies temporal control of DNA replication and links it to the process of mitosis. Initiation of DNA replication requires the integration of two central processes: (1) formation of a prereplication complex and (2) activation of DNA-unwinding and polymerase functions. The former can occur only when Cdk activity is low, whereas the latter is promoted by high Cdk activity (Dahmann et al. 1995; Diffley 1996, 2001; Piatti et al. 1996; Noton and Diffley 2000). Thus, the switch from low Cdk activity to high Cdk activity is critical to proper control of DNA replication. Moreover, because Cdks are inhibitory to the formation of prereplication complexes, reinitiation cannot occur until cells reduce their Cdk activity by passing through mitosis, thereby ensuring the temporal order of S- and M-phases.

Efforts to understand how this periodicity in Cdk activity is achieved have led to a greater understanding of both the positive and negative roles played by the APC/C in cell cycle control. The $\mathrm{APC} / \mathrm{C}$ is required to reduce B-type cyclin levels as cells pass through anaphase and telophase, but the APC/C also restrains the accumulation of B-type cyclins during $\mathrm{G}_{1}$, and its inactivation is required for timely S-phase entry (Irniger and Nasmyth 1997). Moreover, the APC/C is required to coordinate
A
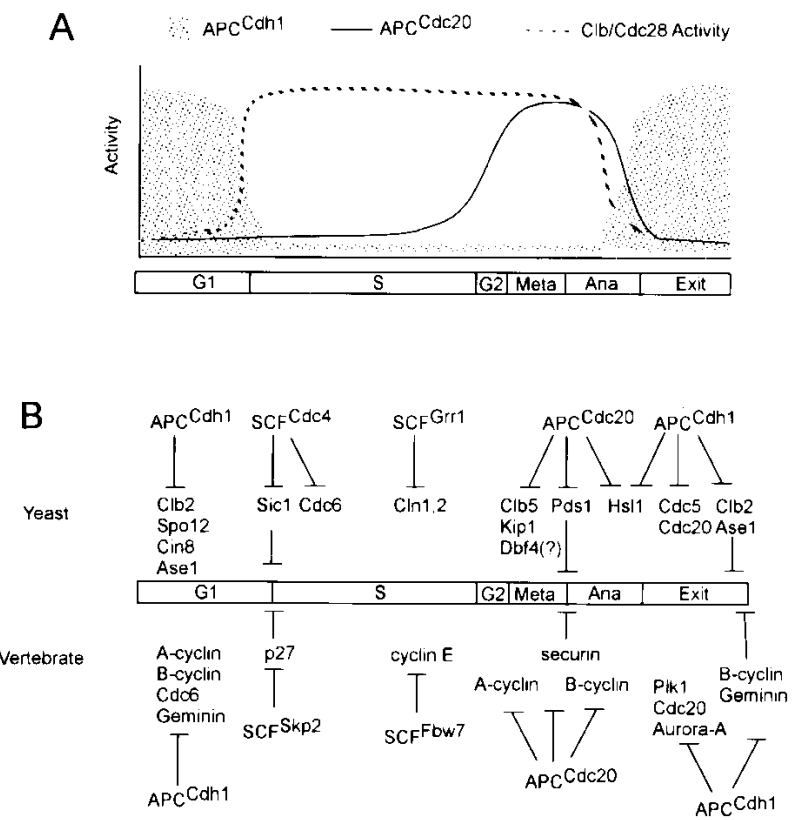

Figure 3. Temporal control and substrates of the APC/C. $(A)$ Periodic activities of $\mathrm{APC}^{\mathrm{Cdc} 20}$, cyclin $\mathrm{B} / \mathrm{Cdc} 2$, and $\mathrm{APC} / \mathrm{C}^{\mathrm{Cdh} 1}$. Cdk kinase activity is high in $\mathrm{S}$ phase and persists to the metaphase-anaphase transition. APC ${ }^{\mathrm{Cdc} 2 O}$ is activated as cells approach metaphase, and this activity is enforced by high Cdc 28 activity. APC ${ }^{C d h 1}$ is activated during exit from mitosis and persists until the $\mathrm{G}_{1} / \mathrm{S}$ transition. $(B)$ Cell cycle targets of the $\mathrm{APC} / \mathrm{C}$ and the SCF in budding yeast and human cells.

chromosome separation at the metaphase-to-anaphase transition in a process that requires Cdk activity.

The necessity that the APC/C be active under conditions of both high and low Cdk activity is reflected in the use of the two activators, Cdc20 and Cdh1, which display differential sensitivity to Cdk activity. APC ${ }^{\mathrm{Cdc} 20}$ functions in the presence of high Cdk activity, and, indeed, this form of the APC/C appears to require $\mathrm{Cdk}$ function for activation (but see below for caveats to this generalization). In contrast, Cdh1 is directly inhibited by Cdks (Zachariae et al. 1998a; Jaspersen et al. 1999; Sorensen et al. 2000, 2001). Thus, the ability of the APC/C to shuffle through states of activation by $\mathrm{Cdc} 20$ and Cdh1 is central to its ability to control Cdk activity through cyclin degradation and the degradation of other substrates. Layered on this control is the activity of $G_{1}$ cyclin/Cdk complexes. Unlike B-type cyclins, $\mathrm{G}_{1}$ cyclins are immune to the action of the $\mathrm{APC} / \mathrm{C}$ and therefore can accumulate when $\mathrm{APC}^{\mathrm{Cdh} 1}$ activity is high. This property is important because $\mathrm{Cln} / \mathrm{Cdc} 28$ activity in budding yeast is required to activate degradation of the B-type cyclin/Cdk inhibitor Sic1 and initiate DNA synthesis (Schwob et al. 1994; Tyers 1996).

Switching off Clb5-dependent Cdk activity and destroying the mitotic inhibitor Pds1 are the sole essential functions of Cdc20 in budding yeast

$\mathrm{APC}^{\mathrm{Cdc} 20}$ plays two essential roles in the early stages of mitosis: (1) degradation of a regulator of sister-chromatid 
cohesion and (2) degradation of Clb5, an S-phase cyclin that potently antagonizes $\mathrm{APC}^{\mathrm{Cdh} 1}$ activity. $\mathrm{APC}^{\mathrm{Cdh} 1}$ is, in turn, required to destroy the bulk of B-type cyclins to allow exit from mitosis (Fig. 3B). The defining event in mitosis is separation of sister chromatids (for review, see Nasmyth 1999; Nasmyth et al. 2000). The bonds that hold sister chromatids together are set up during DNA synthesis through the process of cohesion and are maintained until cells undergo the metaphase-anaphase transition (Fig. 4; Uhlmann and Nasmyth 1998; Tomonaga et al. 2000). The temporal linkage of cohesion with DNA replication provides a means by which to ensure that sister chromosomes are tethered until metaphase and explains why cohesion cannot be established during $G_{2}$. Sister-chromatid cohesion occurs via a multiprotein complex containing Scc1/Mcd1/Rad21, Scc3, Smc1, and Smc3 (Guacci et al. 1997; Michaelis et al. 1997; Furuya et al. 1998; Ciosk et al. 2000). In yeast, cohesion is maintained along the length of the chromosome until metaphase (Tanaka et al. 1999), but in mammalian cells, loss

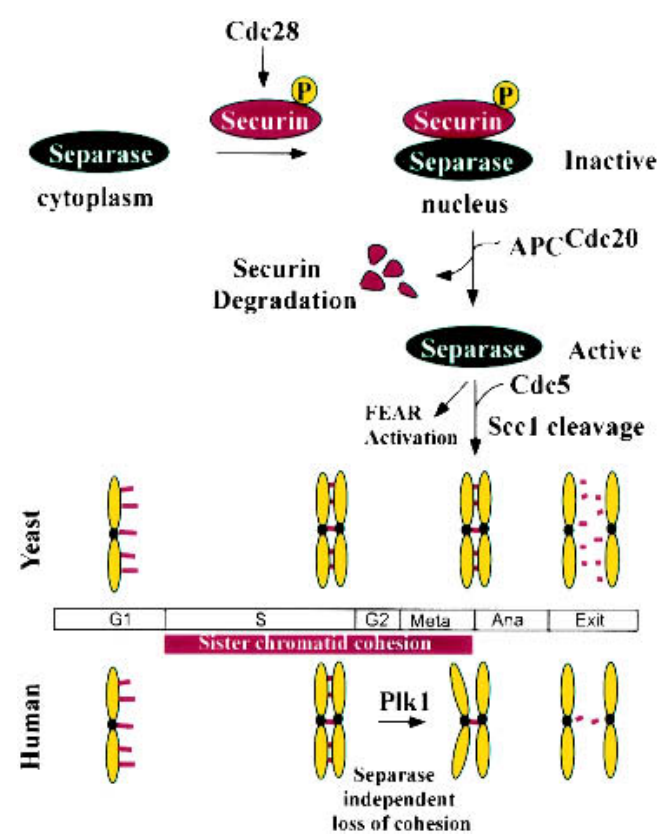

Figure 4. The role of the APC/C in loss of sister-chromatid cohesion at the metaphase-to-anaphase transition. Cohesion is established during $\mathrm{S}$ phase and is lost at the metaphase-anaphase transition through the action of a protease, separase, that cuts Scc1, thereby breaking the bonds that hold sister chromatids together. Separase is initially cytoplasmic and, in budding yeast, is localized to the nucleus in a pathway that is dependent on Cdc28-mediated phosphorylation of Pds1. When conditions for anaphase are met, securin is ubiquitinated by $\mathrm{APC}^{\mathrm{Cdc} 20}$, and separase is released in an active form to cleave Scc1. In budding yeast, Scc1 cleavage is facilitated by Cdc5-mediated phosphorylation (Alexandru et al. 2001). Separase is also required to activate transient release of $\mathrm{Cdc} 14$ from the nucleolus through the Cdc-FEAR (fourteen early anaphase release) pathway. In human cells, loss of cohesion occurs through a polo-kinase (Plk1)-mediated step without cleavage of Scc1 in prophase, followed by a separase-dependent step at the metaphase-anaphase transition. of cohesion is more complex. In an initial step, most cohesin complexes are released from chromosome arms, with a small fraction remaining bound in centromeric regions (Fig. 4; Waizenegger et al. 2000). This initial loss of arm cohesion depends on the Polo protein kinase (Sumara et al. 2002). Complete loss of cohesion occurs upon cleavage of Scc1 by an endoprotease called separase (Esp1 in budding yeast and Cut1 in fission yeast; Uhlmann et al. 1999, 2000; Yanagida 2000; Hauf et al. 2001). Regulation of separase is critical. Inappropriate separase activity can lead to precocious dissociation of sister chromatids. The timing of separase activity is controlled through the activity of a protein generically referred to as securin (Pds1 in budding yeast, Cut2 in fission yeast, and PTTG in mammals). Securin plays a negative role in mitosis by binding to separase and inhibiting its protease activity. Thus, activation of anaphase depends on proper degradation of securin by APC ${ }^{\mathrm{Cde} 20}$ (Cohen-Fix et al. 1996; Funabiki et al. 1996; Yamamoto et al. 1996; Visintin et al. 1997; Lim et al. 1998; Schott and Hoyt 1998; Tinker-Kulberg and Morgan 1999; Zou et al. 1999; Salah and Nasmyth 2000). Degradation of Pds1 liberates active separase, which then cleaves Sccl to promote loss of cohesion (Fig. 4; Ciosk et al. 1998; Uhlmann et al. 1999, 2000).

Cdks play a major role in regulating sister-chromatid separation in yeast (as well as other organisms). First, Cdks phosphorylate core subunits of the APC/C /Cdc16, Cdc23, and Cdc27), which promotes $\mathrm{APC}^{\mathrm{Cdc} 20}$ activation (see below). Second, Cdks play a critical role in a positive function of securin (Fig. 4; Agarwal and CohenFix 2002). In budding yeast, accumulation of Esp1 in the nucleus depends on the presence of securin/Pds1 (Jensen et al. 2001). Similarly, in S. pombe, localization of separase/Cut1 on spindle poles requires securin/Cut2 (Kumada et al. 1998). Recent studies (Agarwal and CohenFix 2002) have revealed that Cdc28 directly phosphorylates Pds1, thereby enhancing its ability to bind to Esp1 and promoting Esp1 nuclear localization. However, Cdkmediated Pds1 phosphorylation does not appear to be required for Pds1 to function as a mitotic inhibitor as cells expressing Pds1 that lack critical Cdk phosphorylation sites are resistant to the microtubule-depolymerizing drug benomyl, unlike pds1s cells. Third, in vertebrate cells, separase is phosphorylated, and this appears to negatively regulate its ability to induce sister-chromatid separation (Stemmann et al. 2001). The kinase responsible has not yet been identified, but Cdc2 is capable of inducing a blockade to sister-chromatid separation even though securin is destroyed. Thus, phosphorylation of separase may provide an additional mechanism for controlling the timing of loss of cohesion.

Once cells have initiated anaphase, they begin to switch off mitotic cyclin activity (Fig. 3A). This process occurs in two phases. First, APC ${ }^{\text {Cdc20 }}$ eliminates the bulk of cyclins present during mitosis, including Clb3 and Clb5 (Shirayama et al. 1999; Baumer et al. 2000; Yeong et al. 2000). Clb5 degradation is particularly important, and, in fact, Pds 1 and Clb5 are the only essential substrates of $\mathrm{APC}^{\mathrm{Cdc} 2 \mathrm{O}}$ in budding yeast as deletion of 
CLB5 and PDS1 suppresses the lethality of $c d c 20 \Delta$ cells (Shirayama et al. 1999). As described in detail below, activation of $\mathrm{APC}^{\mathrm{Cdh} 1}$ requires collaboration between a protein phosphatase Cdc14 and the Cdk inhibitor Sic1, which extinguish Cdh1 phosphorylation and promote assembly of an active APC ${ }^{\mathrm{Cdh} 1}$ complex (Visintin et al. 1998; Jaspersen et al. 1999). One possible interpretation of the data is that, among B-type cyclin complexes, Clb5/Cdk is most active toward Sic1 and Cdh1 during this phase of the cell cycle, and this activity cannot normally be overcome by Cdc14. In the absence of Clb5, normal levels of Cdc14 are sufficient to maintain Sicl and Cdh1 in their unphosphorylated forms despite the presence of other B-type cyclin/Cdk complexes. The second phase of the switch from high to low Bcyclin/Cdk activity comes with the full activation of $\mathrm{APC}^{\mathrm{Cdh} 1}$, which is capable of efficiently destroying Clb2 (Schwab et al. 1997; Visintin et al. 1997). Complete degradation of $\mathrm{Clb} 2$ is required for exit from mitosis. Integrating degradation of Pds1 and Clb5 with activation of APC $^{\text {Cdh1 } 1, ~ t o g e t h e r ~ w i t h ~ t h e ~ f a c t ~ t h a t ~ d e g r a d a t i o n ~ o f ~ P d s 1 ~}$ is required for release of Cdc14 from the nucleolus (Shirayama et al. 1999; Tinker-Kulberg and Morgan 1999), provide an effective mechanism for ensuring that cells exit mitosis only after they have separated their chromosomes.

\section{Spatial control of cyclin degradation}

A major question in the ubiquitination field concerns the spatial and temporal control of ubiquitination, which is largely an unexplored area. In many cases, substrates are thought to be destroyed essentially in an allor-none fashion. However, analysis of B-type cyclin degradation indicates that temporal control of degradation may go hand-in-hand with spatial control. In budding yeast, Clb2 degradation occurs in two waves, a Cdc20dependent pathway that destroys a substantial fraction of Clb2 during anaphase and a second wave of degradation that occurs via APC ${ }^{\mathrm{Cdh} 1}$ during mitotic exit (Lim et al. 1998; Baumer et al. 2000; Yeong et al. 2000). The basis of this differential selectivity is unknown but could potentially reflect localized activation of Cdh1 during mitosis. Perhaps the best example of spatial control in ubiquitination by the APC/C comes from an analysis of human cyclin B-GFP degradation in real time in vivo /Clute and Pines 1999). Cyclin B is localized to chromosomes and spindle poles during prophase and is also diffusely localized in the nucleus. Once the last chromosome is aligned at the metaphase plate, cyclin B-GFP is immediately eliminated from the spindle poles and chromosomes, but most of the cyclin B-GFP remains, only to be eliminated as cells proceed into anaphase (Clute and Pines 1999). Using immunofluorescence, it has also been found that Drosophila cyclin B is lost from spindle poles more rapidly than from other nuclear structures (Huang and Raff 1999). What is not clear is to what extent spatial degradation is controlled by the activity of the APC/C or by some event that renders the target susceptible to ubiquitination. In mammalian cells, some components of the $\mathrm{APC} / \mathrm{C}$, including $\mathrm{APC} 1, \mathrm{CDC} 27$, and $\mathrm{DOC} 1$, are located on centrosomes (King et al. 1995; Jorgensen et al. 1998), but this localization is insufficient to provide a mechanism for this level of control. It will be important to determine to what extent spatial control of cyclin degradation is linked with specific biological activities of cyclins. On a general note, analysis of spatial distribution of proteolysis is complicated by the fact that proteins can also undergo non-ubiquitin-dependent alterations in localization. The development of methods that identify substrate-E3 interactions in living cells may be required to explore these important questions.

\section{Linking the APC/C with degradation of diverse proteins}

Although securin and mitotic cyclins are perhaps the best understood APC/C substrates, a large number of other proteins display cell cycle-regulated degradation via the APC/C (Fig. 3B). Many of these targets have been identified through the use of temperature-sensitive mutations in budding yeast APC/C subunits. These include multiple proteins linked with spindle function, such as the anaphase spindle-elongation-control protein Ase1, the kinesin-related motor protein Cin8, and Cdc20 itself. In budding yeast, both Ase1 and Cin 8 degradation are controlled by APC ${ }^{\text {Cdh1 }}$ (Juang et al. 1997; Hildebrandt and Hoyt 2001). In contrast, degradation of Kip1, a motor protein that appears to function redundantly with Cin8, is Cdc20-dependent (Gordon and Roof 2001). Although these proteins are clearly APC/C substrates and are degraded in a cell cycle-dependent manner, cells expressing nondegradable forms tend to have mild phenotypes, indicating that their degradation is not essential for cell proliferation. For example, although expression of endogenous levels of nondegradable Cin 8 causes an increase in the fraction of cells without spindles, indicating a defect in assembly or maintenance of the mitotic spindle, the cells are viable. A balance between spindle motor forces is important for ensuring proper spindle formation. Because overexpression of Cin8 can disturb spindle function and cause premature elongation of spindles, it seems likely that degradation of Cin 8 during $G_{1}$ provides a mechanism for resetting the motor activity to low levels prior to assembly of the mitotic spindle later in the cell cycle (Hildebrandt and Hoyt 2001). This would predict that Kar3 (Hoyt and Geiser 1996), the motor protein that functions in opposition to Cin8, might also display cell cycle-regulated abundance.

Aurora-A kinase family members are localized to spindle-pole bodies and have been implicated in centrosome duplication and separation and in spindle assembly. In Xenopus and mammalian tissue culture cells, aurora-A accumulates in $G_{2} / M$ and is absent in $G_{1}$. Recent work has shown that aurora-A is ubiquitinated by APC $^{\text {Cdh1 }}$ (Castro et al. 2002; Taguchi et al. 2002). The budding yeast homolog of aurora is Ipll. Although the levels of Ipll also vary in the cell cycle, it has not yet been shown that Ipl1 is subject to regulation by the APC/ C. Aurora family members have been linked with cancer 
in humans, and cancers frequently display elevated aurora levels, in some cases owing to increased gene dosage. High levels of aurora do not alter centrosome duplication directly but induce cells to undergo an aberrant mitosis without cytokinesis, producing tetraploid cells in $G_{1}$ (Meraldi et al. 2002). In the absence of p53, these cells pass through $S$ phase and enter into an aberrant mitosis because of the presence of extra centrosomes, giving rise to aneuploid cells. Thus, the ability of APC ${ }^{\mathrm{Cdh} 1}$ to keep aurora levels in check would appear to be important in maintaining ploidy.

The APC/C has also been linked to the control of DNA synthesis. In metazoans, Cdc6 and Cdt1 collaborate to establish prereplication complexes at the $G_{1} / S$ transition. Cdc6 and Cdt1 assemble at sites of replication initiation and recruit MCM proteins onto chromatin to establish active replication complexes (for review, see Lygerou and Nurse 2000; Diffley and Labib 2002). Both Cdc6 and Cdt1 are regulated through control of their localization, and Cdc6 is additionally regulated by its abundance. Human Cdc6 protein levels are low in $\mathrm{G}_{1}$, in part because of the action of $\mathrm{APC}^{\mathrm{Cdh} 1}$ (Petersen et al. 2000). Cdc 6 is ubiquitinated by $\mathrm{APC}^{\mathrm{Cdh} 1}$ in vitro, and Cdh1 is limiting for its accumulation in tissue culture cells. The ability of Cdc6 to accumulate and assemble into replication complexes will likely depend on inactivation of Cdh1 at the $\mathrm{G}_{1} / \mathrm{S}$ transition (see below). The critical role played by Cdt1 in MCM loading dictates that its activity be tightly controlled after initiation. This is accomplished through the action of geminin, a small protein that binds to Cdt1 and blocks its activity (Wohlschlegel et al. 2000). Geminin is cell cycleregulated; it is present during $S$ and $G_{2}$ phases, but is destroyed as cells proceed through the metaphaseanaphase transition (McGarry and Kirschner 1998; Nishitani et al. 2001). Maintaining low geminin levels during $\mathrm{G}_{1}$ allows for loading of $\mathrm{Cdt} 1$ onto origins. Geminin was initially identified in a screen for substrates of the Xenopus APC/C (McGarry and Kirschner 1998). Although the form or forms of the APC/C that are capable of ubiquitinating geminin have not been determined, the pattern of geminin expression through the cell cycle suggests that Cdh1 is responsible for its turnover.

The APC/C has also been implicated in the turnover of additional components of the budding yeast replication pathway (Fig. 3B). The protein kinase Cdc7 is required for initiation of DNA synthesis and is regulated by Dbf4, whose protein levels are cell cycle-regulated. Once initiation is complete, cells inactivate Cdc7 by destroying Dbf4 via APC ${ }^{\mathrm{Cdc} 20}$-catalyzed ubiquitination /Cheng et al. 1999; Oshiro et al. 1999; Ferreira et al. 2000). Mutations in $\mathrm{Dbf} 4$ that block efficient ubiquitination do not induce cell cycle arrest; Dbf4 degradation is therefore not essential for cell division. Mammalian Dbf4 is also cell cycle-regulated and may use the APC/C to control its stability. In contrast to Dbf4, the levels of Cdc6 during $S$ and $G_{2}$ phases in budding yeast are controlled by SCF ${ }^{C d c} 4$ in conjunction with Cdk-mediated phosphorylation (Drury et al. 1997, 2000; Perkins et al. 2001).

\section{Vertebrate Cdh1 and $G_{1} / S$ control}

Although the role of Cdh1 in $\mathrm{G}_{1}$ control is well characterized in yeast, significantly less is known about Cdh1 function in animal cells. However, recent work has shown that Cdh1 is not required for cell viability and proliferation in DT40 chicken cells (Sudo et al. 2001). As might have been expected, these cells displayed increased levels of mitotic cyclins in $\mathrm{G}_{1}$. Thus, these cells are refractory to inhibition by rapamycin, which induces the Cdk inhibitor p27. A major complication with interpretation of this work is that the chicken genome has at least three other Cdh1 homologs (Wan and Kirschner 2001; see below), and it is possible that one or more of these is partially redundant with Cdh1 for important mitotic functions in these cells.

\section{Substrate recognition}

\section{Destruction boxes and KEN boxes}

The first motif found to be necessary for the degradation of an APC/C substrate was the destruction box. When Glotzer et al. (1991) first showed that mitotic cyclins were degraded via the ubiquitin system, they also showed that an N-terminal 91-amino-acid fragment was sufficient for ubiquitination and degradation, and that it could cause the degradation of an unrelated protein when the two were fused. Inspection of the $\mathrm{N}$ termini of the known cyclins revealed a conserved short motif that might be important either for substrate recognition or for ubiquitination. This motif was termed the destruction box. Mutagenic analysis has identified the degenerate core destruction-box motif to be RxxLxxxxN (Glotzer et al. 1991; King et al. 1996), although there are some clear differences in the destruction boxes of A- and B-type cyclins (Glotzer et al. 1991; King et al. 1996; Klotzbucher et al. 1996; Geley et al. 2001) and some flexibility at the last position. Of course, such a small motif occurs frequently and does not, by itself, contain sufficient information to confer APC/C-dependent ubiquitination on a protein. Little is understood about other elements located near the destruction box that are required for its proper recognition. Clearly, such elements may be highly degenerate and only recognizable at the structural level. Even when a small piece of an APC/C substrate (such as a 27-amino-acid fragment of a mitotic cyclin; King et al. 1996) can confer degradation on an unrelated protein, one must always be cautious in assuming that all of the recognition elements are contained in the transferred sequence. Degenerate elements, not just including the ubiquitinated lysines themselves, may be present in the fusion partner. Destruction boxes are widespread and have been found in the majority of APC/C substrates.

A second degradation motif, the KEN box, was only identified in 2000 (Pfleger and Kirschner 2000). It was suspected that human Cdc20 might contain a novel motif because it lacked an identifiable destruction box yet was a substrate for APC ${ }^{\mathrm{Cdh} 1}$ in Xenopus egg extracts. Deletion analysis narrowed the motif to the first $\sim 100$ amino acids of the protein, and alanine-scanning muta- 
genesis identified four amino acids as essential: KENxxxN. Given that other Cde20 homologs contain aspartic acid in place of the second asparagine, it was proposed that the minimal KEN box consists of $\operatorname{KENxxx}(\mathrm{N} / \mathrm{D})$, although it is plausible that glutamic acid and possibly other amino acids may also be allowed in the terminal position. Indeed, the budding yeast Hsl1 protein contains a functional KEN box consisting of KENxxxE (Burton and Solomon 2001), the KEN box of the yeast Clb2 protein is KENxxxS (Hendrickson et al. 2001), and the KEN box of human securin is KENxxxG (Zur and Brandeis 2001). Few KEN boxes have been examined in any detail, so this consensus may evolve, particularly if suboptimal KEN boxes retain significant function. Like the destruction box, the KEN box is portable, and a 28-amino-acid section of human Cdc20 containing the KEN box could destabilize an unrelated protein, though not as well as larger pieces of Cdc20, suggesting that there may be additional determinants for recognition. So far, only a modest number of APC/C substrates have been found to have KEN boxes, although this number will grow as more substrates are examined for their presence and as we fine-tune our understanding of what sequences constitute functional motifs. Some substrates require both a destruction box and a KEN box (Petersen et al. 2000; Burton and Solomon 2001; Hendrickson et al. 2001; Jacobs et al. 2001; Zur and Brandeis 2001). In such cases, initial identification of a necessary destruction box may delay recognition of an essential KEN box.

The existence of well-characterized Destruction boxes and KEN boxes does not preclude the possibility of additional degradation motifs. For instance, a new motif, the A box, has just been found to be essential for the $\mathrm{APC}^{\mathrm{Cdh} 1}$-mediated degradation of Xenopus Aurora-A (Littlepage and Ruderman 2002).

\section{Direct binding to Cdc20 and Cdh1}

When Cdc20 and Cdh1 were found to confer substrate specificity on the APC/C, it was generally assumed that they would bind substrates directly and recruit them to the APC/C. This was certainly the simplest explanation. However, through years of study, there was no evidence that Cdc20 or Cdh1 bound substrates directly, necessitating that other models be considered. For instance, the distinct but overlapping specificities that Cdc20 and Cdh1 conferred on the APC/C suggested that each activator might cause a different substrate-binding site on the APC/C to open. Given the inelegance of this model, it was a relief when four reports appeared within a twoweek span last year showing various aspects of the direct recognition of substrates by $\mathrm{Cdc} 20$ and $\mathrm{Cdh} 1$ in diverse systems.

Schwab et al. (2001) showed by coimmunoprecipitation that budding yeast Cdc20 and Cdh1 were associated with substrates. The specificity of the associations paralleled the degradation requirements. Thus, Cdc20, but not Cdh1, bound to Pds1, which requires Cdc20 for its degradation, and Cdh1, but not Cdc20, bound to Clb2,
Clb3, and Cdc5, all of which require Cdh1 for their degradation. Mutation of the destruction boxes in Clb2 or Cdc5 did not affect the association with Cdh1, suggesting either that there is another degradation motif, or that degradation motifs are not involved in this interaction. A KEN box has since been identified in Clb2 (Hendrickson et al. 2001), although whether it mediates the interaction with Cdh1 has not been tested. Hilioti et al. (2001) also examined the association of Pds1 with Cdc20. They found that the destruction box in Pds1 was necessary for this association and that Pds1 produced in Escherichia coli could bind to Cdc20 produced by in vitro translation, strongly suggesting that the interaction was direct. Importantly, they also showed that the spindle assembly checkpoint (see below) had no effect on substrate binding.

Pfleger et al. (2001a) examined substrate recognition in the Xenopus system. They also found by coimmunoprecipitation that substrates could associate with Cdc20 and Cdh1 and that the specificity of the association followed the specificity for degradation. In this system, Cdc20 has a strong preference for destruction-box-containing substrates, whereas $\mathrm{Cdh} 1$ has a strong preference for KEN boxes. Deletion analysis identified the N-terminal 120 amino acids of Cdc20 and 125 amino acids of Cdh1 as the substrate-binding regions. These domains, expressed in E. coli, could bind to substrates produced by in vitro translation (followed by gel filtration, to rule out association with other factors) or by expression in E. coli. Thus, these interactions were direct. Finally, Burton and Solomon (2001) examined the binding of the budding yeast Hsl1 protein to $\mathrm{Cdc} 20$ and Cdh1. Coimmunoprecipitation from yeast extracts showed that both the destruction-box and KEN-box motifs were important for the association of full-length Hsl1 with Cdc20 and Cdh1. In addition, they showed that a fragment of Hsll containing both degradation motifs and expressed in E. coli bound to $\mathrm{Cdc} 20$ and $\mathrm{Cdh} 1$ expressed in and purified from baculovirus-infected insect cells. Analogous to the coimmunoprecipitation experiments from yeast extracts, this binding was completely eliminated by double mutation of the destruction box and the KEN box.

Taken together, these results show the direct binding of $\mathrm{APC} / \mathrm{C}$ substrates to Cdc20 and Cdh1 and the importance of the destruction box and the KEN box for these interactions, thus providing biochemical explanations for the roles of these degradation motifs and of the "APC/C activators." So far, no experiments have addressed whether Cdc20 and Cdh1 can activate the $\mathrm{APC} / \mathrm{C}$ by means other than substrate recruitment.

Some of the preceding experiments also began to address the next step in the process, binding of Cdc20 and Cdh1 to the APC/C. Schwab et al. (2001) identified the "C-box" (DR/F/Y)IPxR) in the N-terminal regions of all Cdc20 and Cdh1 homologs from the two yeasts, Drosophila, Xenopus, humans, and mouse. Deletion of the C-box eliminated Cdh1 function and its ability to coprecipitate with the APC/C. In contrast, Pfleger et al. (2001a) found that the N-terminal half of Cdc20 and Cdh1 bound substrates, but not the APC/C. They sug- 
gested that the APC/C-binding region lies within the C-terminal WD40 repeats. Such a model parallels the structure of the SCF in which the F-box is used as the interchangeable docking module of the substrate-binding component. There is currently no information regarding to which APC/C subunit $\mathrm{Cdc} 20$ and $\mathrm{Cdh} 1$ may bind.

\section{Do destruction boxes and KEN boxes form bipartite degradation motifs?}

For most of the time since their discoveries, destruction boxes and KEN boxes have been considered independent entities. This view was natural given the simple observations that mutation of the element stabilized the protein in which it was found and that each element was portable and could confer degradation on unrelated proteins. In addition, there has been a strong tendency, particularly in the Xenopus system, for KEN-box-containing substrates to be degraded via Cdh1, not Cdc20, suggesting independent recognition. Some recent experiments, however, muddy this simple picture and lead to a more nuanced view of these degradation motifs.

At least five well-studied proteins-human CDC6 and securin, Drosophila cyclin A, and budding yeast Hsl1 and Clb2-require that both a destruction box and a KEN box be present for their efficient degradation (Petersen et al. 2000; Burton and Solomon 2001; Hendrickson et al. 2001; Jacobs et al. 2001; Zur and Brandeis 2001), suggesting that these motifs function as a single unit to promote degradation. The case of Hsll illustrates the important points (Burton and Solomon 2000, 2001). Hsl1 is stabilized in vivo by mutation of either its destruction box or its KEN box. Degradation in the presence of $\mathrm{APC}^{\mathrm{Cdc} 20}$ or of $\mathrm{APC}^{\mathrm{Cdh} 1}$ shows the same requirement for both of these degradation motifs, indicating in particular that a KEN box can influence recognition by $\mathrm{Cdc} 20$ and that a destruction box can influence recognition by Cdh1. These requirements for degradation contrast with those for binding of Hsl1 to Cdc20 and Cdh1. For example, mutation of the KEN box stabilized Hsll but had no effect on Cdc20-binding, whereas mutation of the destruction box stabilized Hsll but had only a minimal effect on the binding of Hsll to Cdh1. These findings indicate that binding to $\mathrm{Cdc} 20$ or Cdh1 is not sufficient for efficient degradation. It appears that both $\mathrm{Cdc} 20$ and Cdhl have two docking sites, one for a destruction box and one for a KEN box, and that both must be engaged for efficient degradation of Hsll. Although one site may provide tight binding, the second site still plays an important role, perhaps in the proper orientation of the substrate for its presentation to the APC/C. These views are supported by the generally close spacing (in primary sequence, presumably also in three dimensions) of these motifs in proteins found to have two functional motifs, although their relative order can vary: 53 amino acids (aa) in Hs11, 75 aa in Clb2, 25 aa in human CDC6, 33 aa in Drosophila cyclin A, 52 aa in human securin, and 30 aa in human Nek2.

These observations suggest some interesting specula- tions. Perhaps a number of APC/C substrates, conceivably even most of them, have sequences compatible with binding to both the destruction-box and the KEN-box binding sites on Cdc20 and/or Cdh1. Clearly, only one of these degradation motifs has been found in most APC/C substrates. This canonical motif may provide most of the energy for the substrate-Cdc20/Cdh1 interaction, and a degenerate motif, not recognizable by a simple analysis of the primary sequence of the substrate, may plug into the second motif-binding site of Cdc20/Cdh1 and, via a weaker interaction, serve to position the substrate for presentation to the APC/C. The proximity of these motifs in some substrates, and their potentially degenerate nature, may explain the general observation that destruction boxes and KEN boxes are portable. In addition, the portable regions have always been much larger than the basic motifs. Of course, such hypothesized weak motifs will be difficult to identify and will require structural analysis to define. Nevertheless, even quite obvious second motifs often go undiscovered for a long time. For instance, budding yeast Clb2 has long been a model destruction-box-containing APC/C substrate. Because mutation of the destruction box stabilized the protein, there was no need to search for additional motifs. Nevertheless, it was recently found that $\mathrm{Clb} 2$ has a functional KEN box and that both motifs must be present for degradation of Clb2 (Hendrickson et al. 2001). Indeed, even some of the substrates that initially helped define the KEN box (Pfleger and Kirschner 2000), such as Nek2 and B99, have destruction boxes as well (Hames et al. 2001; C. Pfleger and M. Kirschner, pers. comm.). So far there seems to be a general trend for proteins with KEN boxes to also have clearly identifiable destruction boxes, but not the converse. Perhaps binding to the destruction box provides the major positioning of the substrate, thus substrate-Cdc20 interactions can get away without a strong KEN-box interaction, but substrate-Cdh1 interactions, which may be centered on the KEN box, still require a significant interaction via the destruction box.

\section{APC/C regulation}

As mentioned above, the SCF ubiquitin ligases are constitutively active; regulation occurs at the level of SCF substrate recognition, where only phosphorylated SCF substrates are ubiquitinated. In contrast, as discussed in the following sections, the APC/C ubiquitin ligase itself is regulated and its activity oscillates in a cell cycledependent manner (Fig. 3A). One component of this oscillatory mechanism is phosphorylation of core APC/C subunits, which occurs upon entry into mitosis and is required for optimal APC/C activity. These phosphorylation events are thought to be mediated by $\mathrm{Cdc} 2 / \mathrm{cyclin}$ $\mathrm{B}$ and Polo protein kinases and have been shown to enhance the Cdc20-APC/C interaction. In contrast, dephosphorylation of these subunits, possibly by PP1 or PP2A, decreases APC/C activity and Cdc20-binding. In addition, PKA-mediated phosphorylation of the core APC/C subunits inhibits APC/C activity, although the mechanism of this inhibition is presently unknown. 
APC/C activity is also controlled through the APC/C activators, Cdc20 and Cdh1. Cdc20 levels fluctuate in a cell cycle-dependent manner, through transcriptional and posttranslational mechanisms, thus restricting $\mathrm{APC}^{\mathrm{Cdc} 20}$ activity by limiting the amount of Cdc20 available to bind to the APC/C. Finally, Cdh1 undergoes inhibitory phosphorylation by Cdks that prevents $\mathrm{APC} / \mathrm{C}$ binding, thus restricting $\mathrm{APC}^{\mathrm{Cdh} 1}$ activity to points in the cell cycle when Cdk activity is low.

\section{Phosphorylation of core $A P C / C$ subunits}

Prior to the full molecular characterization of the APC/ C, elegant biochemical experiments in Xenopus and clam systems had shown that the cyclin ubiquitination machinery was inactive during interphase and active during mitosis (Félix et al. 1990; Hershko et al. 1994; King et al. 1995; Lahav-Baratz et al. 1995; Sudakin et al. 1995). Phosphorylation of the interphase APC/C by mitotic Cdks stimulated cyclin ubiquitination (Félix et al. 1990; Hershko et al. 1994; King et al. 1995; Lahav-Baratz et al. 1995; Sudakin et al. 1995), whereas phosphatase treatment of the mitotic form resulted in APC/C inactivation (Lahav-Baratz et al. 1995). It is now well established that one or more subunits of the APC/C are phosphorylated during mitosis in frogs, humans, clams, and in both fission and budding yeasts (Peters et al. 1996; Yamada et al. 1997; Patra and Dunphy 1998; Kotani et al. 1998, 1999; Rudner and Murray 2000; Golan et al. 2002). These subunits include APC1, Cdc27, Cdc16, and Cdc23. However, the responsible kinase(s) and how phosphorylation stimulates APC/C activity have been the subject of debate. Only recently have the functions of APC/C phosphorylation become clearer.

Work in clam and Xenopus systems mentioned above implicated $\mathrm{Cdc} 2 /$ cyclin $\mathrm{B}$ as the protein kinase responsible for stimulating APC/C activity (Félix et al. 1990; Hershko et al. 1994; King et al. 1995; Lahav-Baratz et al. 1995; Sudakin et al. 1995; Shteinberg et al. 1999). In addition, Xe-9/Cks1/Suc1, known to bind to Cdc2, enhanced phosphorylation of the $\mathrm{Cdc} 27$ subunit and further stimulated APC/C activity (Patra and Dunphy 1998; Shteinberg et al. 1999). However, data obtained from several different experimental systems have also suggested a role for the Polo-like protein kinase (Plk/Cdc5/Plo1) in APC/C activation. In Xenopus egg extracts, immunodepletion of Plk prevented mitotic cyclin degradation and mitotic exit in cytostatic factor (CSF)-arrested extracts treated with calcium (Descombes and Nigg 1998). Moreover, an inactive version of Plk blocked cyclin degradation as well as the degradation of exogenously added APC/C substrates upon $\mathrm{Ca}^{2+}$ addition (Descombes and Nigg 1998). Experiments using animal cells showed that Plk could phosphorylate APC1, Cdc27, and Cdc16 in vitro, and Plk could coimmunoprecipitate with the APC/C in extracts from these cells (Kotani et al. 1998, 1999). Similarly, in S. pombe, Plo1 (Plk/Cdc5) was found by several criteria to interact directly with Cdc23/Cut23, and disruption of this interaction resulted in a metaphase arrest with stable securin/Cut2 and cyclin pro- teins (May et al. 2002). As often happens, the resolution to this debate may be that both stories are true: Core APC/C subunits from highly purified preparations in clams were found to be differentially phosphorylated by $\mathrm{Cdc} 2$ and Plk, and phosphorylation by both kinases was necessary for full cyclin ubiquitination activity (Golan et al. 2002).

Recently, the in vivo sites of phosphorylation on the APC/C subunits Cdc27 (APC3), Cdc16 (APC6), and Cdc23 (APC8) in S. cerevisiae were determined by a mutagenesis approach and found to correspond directly to the sites phosphorylated by Cde2 8 in vitro (Rudner and Murray 2000). In contrast to Cdc28, Cdc5 (Plk) was still able to phosphorylate the mutant forms of the Cdc16 and Cdc27 subunits in vitro, even though phosphorylation of these subunits was no longer detected in vivo (Rudner and Murray 2000). These findings implicate Cdc 28 as the primary kinase responsible for phosphorylation of these $\mathrm{APC} / \mathrm{C}$ subunits in budding yeast. Interestingly, mutation of these APC/C phosphorylation sites was not lethal, leaving open the possibility that Cdc5/Plk may also influence APC/C activity by phosphorylating other APC/C subunits, analogous to the findings in clam (Rudner and Murray 2000; Golan et al. 2002). It is also conceivable that mitotic phosphorylation of the APC/C is not absolutely required for some basal level of activity in cells. Taken together, these studies implicate a role for both Cde2/cyclin B and Plk in APC/C core subunit phosphorylation and activation.

\section{The role of $A P C / C$ phosphorylation}

Data from several laboratories suggest that at least one mechanism by which phosphorylation stimulates the $\mathrm{APC} / \mathrm{C}$ is through increased binding of Cdc20. In human cells, mitotic, phosphorylated APC/C was shown to bind more avidly to hCDC20 than APC/C isolated from other cell cycle stages, and only the mitotic form could stimulate cyclin ubiquitination in vitro (Fang et al. 1998a; E.R. Kramer et al. 1998). In contrast, phosphatase treatment of mitotic APC/C resulted in reduced hCdc 20 binding and weaker APC/C activation (Kramer et al. 2000). Similar results have been reported in clams, where $\mathrm{Cdc} 20$ was only found to stimulate ubiquitination of APC/C substrates using the mitotic, phosphorylated form of the APC/C (Shteinberg et al. 1999). In budding yeast, cdc28 mutant strains have reduced levels of Cdc20 bound to the APC/C resulting in lowered $\mathrm{APC}^{\mathrm{Cdc} 20}$ activity and a mitotic delay (Rudner et al. 2000). In addition, mutation of the potential Cdc28 phosphorylation sites within $\mathrm{Cdc} 27, \mathrm{Cdc} 16$, and Cdc23 in budding yeast were found to drastically reduce (but not eliminate) Cdc20 binding to the APC/C in vivo, whereas APC ${ }^{\mathrm{Cdh} 1}$ activity was unaffected (Rudner and Murray 2000). It will be of interest to determine if increasing the level of Cdc20 in these APC/C phosphorylation mutants might suppress the mitotic delay by enhancing the Cdc20-APC/C interaction. It is also not clear at present whether removal of phosphates from core APC/C subunits occurs as yeast cells exit mitosis and assemble $\mathrm{APC}^{\mathrm{Cdh} 1}$ complexes. In prin- 
ciple, mitotic exit could be coupled to APC/C dephosphorylation via the Cdc14 phosphatase (see below).

In addition to these positive-acting phosphorylations, the APC/C also appears to be negatively regulated by phosphorylation of core subunits. For instance, protein kinase A (PKA) can inhibit APC/C activity in both fission and budding yeast in vivo, and deletion of pka1 in fission yeast can suppress mutations in the APC/C (Yamashita et al. 1996; Yamada et al. 1997; Anghileri et al. 1999|. In human and mouse cell lines, PKA can phosphorylate both APC1 and Cdc23 and inhibit cyclin ubiquitination by the APC/C in vitro (Kotani et al. 1998, 1999). In synchronized HeLa cells, PKA activity rapidly increased as cells entered mitosis and fell sharply as cells reached metaphase, consistent with a role as an APC/C inhibitor (Kotani et al. 1998). Precisely how these negative phosphorylation events affect APC/C activity remains to be elucidated.

In addition to phosphorylating core APC/C subunits, Cdc2 can also phosphorylate Cdc20 in higher eukaryotes (Weinstein 1997; Lorca et al. 1998; Kramer et al. 2000; Ohtoshi et al. 2000). However, the role of this phosphorylation is unclear. Kotani et al. (1999) found that Cdc20 phosphorylation is not necessary for its binding to the APC/C, but that it is essential for Cdc20 to promote ubiquitination in vitro. In contrast, Kramer et al. (2000) found that phosphorylation of $\mathrm{Cdc} 20$ affects neither its ability to bind to nor to activate the APC/C in vitro. Finally, Yudkovsky et al. (2000) found that Cdc20 is phosphorylated and unable to activate the APC/C in checkpoint-arrested cells. Clearly, additional work will be required to reconcile these differences and to determine if and how phosphorylation of Cde20 functions in the mitotic checkpoint response. In contrast, negative regulation of Cdh1 by Cdk phosphorylation has been well documented (see below).

\section{Degradation of $C d c 20$}

In yeast and somatic cells, Cdc20 protein levels oscillate during the cell cycle through a combination of transcriptional and posttranslational mechanisms. The transcription and protein expression profile for CDC20 is much like that of mitotic cyclins, and it is therefore thought that mitotic kinase activity may regulate CDC20 expression (Prinz et al. 1998). Consistent with this interpretation is the observation that Cdc20 is only present in proliferating cells (Gieffers et al. 1999). Cdc20 is undetectable in $G_{1}$, begins to accumulate in late $S$ phase, peaks at the $G_{2} / M$ phase of the cell cycle, and then disappears in late mitosis by an $\mathrm{APC}^{\mathrm{Cdh} 1}$-dependent mechanism (Weinstein 1997; Charles et al. 1998; Fang et al. 1998a; Prinz et al. 1998; Shirayama et al. 1998; Pfleger and Kirschner 2000; Huang et al. 2001). APC ${ }^{\mathrm{Cdh} 1}$-mediated $\mathrm{Cdc} 20$ destruction helps produce a smooth transition from $\mathrm{APC}^{\mathrm{Cdc} 20}$ to $\mathrm{APC}{ }^{\mathrm{Cdh} 1}$ activity as cells proceed from mitosis into $G_{1}$, ensuring that a single form of the APC/C predominates at each cell cycle stage.

The mechanism by which Cdc20 degradation is initiated and how cells switch from the $\mathrm{APC}^{\mathrm{Cdc} 20}$ to the
$\mathrm{APC}^{\mathrm{Cdh} 1}$ form in late mitosis is not entirely clear. However, Cdc20, like cyclin, is likely to sow the seeds of its own destruction by leading to Cdh1 activation. One factor contributing to this switch has been the finding that $\mathrm{APC}^{\mathrm{Cdc} 20}$ initiates mitotic cyclin degradation in mitosis (Lim et al. 1998; Shirayama et al. 1999; Baumer et al. 2000; Yeong et al. 2000), thus enabling the process of Cdk inactivation, Cdh1 dephosphorylation, and binding of Cdh1 to the APC/C to ensue (see below). In the same vein, Cdc20-mediated degradation of securin results in the liberation of separase, which not only promotes sister-chromatid separation, but is also involved in the release of the Cdh1 phosphatase, Cdc14, from the nucleolus in early mitosis (Stegmeier et al. 2002). One of the results of this pathway is the dephosphorylation of Cdh1, thereby promoting APC/C-Cdh1 binding. Whether these two events are sufficient to induce a switch from APC ${ }^{\mathrm{Cdc} 20}$ to APC ${ }^{\mathrm{Cdh} 1}$ or if dephosphorylation of core APC/C subunits also plays a role remains to be seen.

\section{Phosphorylation of Cdh1}

Initial insight into the role of phosphorylation in the control of Cdh1 came from studies in S. cerevisiae. Unlike Cdc20, Cdh1 levels are relatively constant in the cell cycle (Prinz et al. 1998; Zachariae et al. 1998a; Jaspersen et al. 1999). However, Cdh1 was found to undergo cell cycle-dependent phosphorylation, being unphosphorylated in $\mathrm{G}_{1}$ and early $S$ phase, and then phosphorylated during late $S$ phase, $G_{2}$, and mitosis (Zachariae et al. 1998a; Jaspersen et al. 1999). Phosphorylation of Cdh1 inhibits APC/C activation by preventing Cdh1 binding to the APC/C (Zachariae et al. 1998a; Jaspersen et al. 1999). Interestingly, when all Cdk phosphorylation consensus sites within budding yeast Cdh1 were mutated, Cdh1 bound to the APC/C constitutively, resulting in an inability to accumulate mitotic cyclins and to progress through mitosis (Zachariae et al. 1998a). Thus, Cdh1 is active and binds avidly to the APC/C in $G_{1}$ and late mitosis, when Cdc28 activity is low, but is rendered inert during the rest of the cell cycle, when Cdc28 activity is high. The combined regulation of Cdc20 and Cdh1 ensure that only one form of the $\mathrm{APC} / \mathrm{C}$ is active at any time (Fig. 3A).

Inactivation of $\mathrm{APC}^{\mathrm{Cdh} 1}$ by $\mathrm{Cdc} 28$-mediated phosphorylation during the $G_{1} / S$-phase transition is a gradual process requiring both $\mathrm{G}_{1}$-phase and $\mathrm{S}$-phase cyclins (Zachariae et al. 1998a; Huang et al. 2001; Yeong et al. 2001). In agreement with this observation, a genetic screen for APC/C inhibitors that prevent Clb2 degradation identified $\mathrm{G}_{1}$-phase, S-phase, and mitotic cyclins (Bolte et al. 2002). It therefore seems likely that multiple cyclin-Cdc28 complexes can mediate Cdh1 phosphorylation and inactivation. Interestingly, this screen also identified Ime1, a meiosis-specific kinase related to Cdc28 that could phosphorylate Cdh1 and prevent APC/ C-binding, suggesting that this mechanism of inhibition might also be used during meiosis (Bolte et al. 2002). Cdh1 orthologs in fission yeast and higher eukaryotes 
undergo similar regulation in the cell cycle via $\mathrm{Cdk}$ phosphorylation (Lukas et al. 1999; Blanco et al. 2000; Kramer et al. 2000; Listovsky et al. 2000; Sorensen et al. 2000; Bembenek and Yu 2001).

In budding yeast, Cdh1 is dephosphorylated late in mitosis by the dual-specificity phosphatase Cdc14, a protein representing the downstream effector of the mitotic exit network (MEN; Visintin et al. 1998; Jaspersen et al. 1999; Shou et al. 1999; Bardin and Amon 2001). The nucleolar protein Net1/Cfil sequesters Cdc14 in the nucleolus during $\mathrm{G}_{1}$, S-phase, and early mitosis (Shou et al. 1999; Straight et al. 1999; Visintin et al. 1999). Cdc14 release and Cdh1 dephosphorylation occur following nuclear division that is dependent on the MEN pathway (Visintin et al. 1998; Shou et al. 1999; Bardin et al. 2000). The top of the MEN signaling network consists of the Ras-like GTP-binding protein Tem1, the putative exchange factor Lte1, and the putative GAP complex BfalBub2. The exchange of GDP for GTP on Tem1 by Lte1 (which is restricted to the bud cortex) is presumed to occur following entry of the spindle pole body (yeast centrosome, where Tem 1 is localized) into the bud (Bardin et al. 2000; Pereira et al. 2000). These events initiate a protein kinase signaling cascade involving Cdc5, Cdc15, Dbf2, Dbf20, and an associated protein called Mob1, culminating in the release of Cdc14 from Net1/Cfil in the nucleolus (for review, see Morgan 1999; Bardin and Amon 2001; McCollum and Gould 2001). Cdh1 is then dephosphorylated by Cdc14, enabling Cdh1 to bind to the APC/C and promote mitotic cyclin degradation and consequent Cdc28 inactivation and mitotic exit (Visintin et al. 1998; Zachariae et al. 1998a; Jaspersen et al. 1999; Shou et al. 1999). Cdc14 further reduces Cdc28 activity in late mitosis by dephosphorylating the Sic1 transcription factor Swi5 and Sic1 itself, resulting in increased transcription and enhanced stability of Sic1 (Visintin et al. 1998).

Homologs of Cdc14 and other members of the MEN have been identified in diverse organisms (for reviews, see Balasubramanian et al. 2000; Bardin and Amon 2001; McCollum and Gould 2001; Pereira and Schiebel 2001). In $S$. pombe, a pathway known as SIN (septation initiation network) shares many components with the MEN (McCollum and Gould 2001; Oliferenko and Balasubramanian 2001). However, in contrast to $S$. cerevisiae, mutations in the SIN genes do not result in mitotic arrest with high Cdc2 activity, but instead cause cytokinesis and septation defects. In addition, the Clp1/Flp1 phosphatase, the apparent $S$. pombe Cdc14 ortholog, appears to inhibit Cdc2 activity by antagonizing the removal of inhibitory phosphates on $\mathrm{Cdc} 2$ rather than by promoting cyclin degradation (Cueille et al. 2001; Trautmann et al. 2001). In contrast, human cells possess two Cdc14 orthologs (Cdc14A and Cdc14B). Cdc14A can dephosphorylate Cdh1 in vitro and stimulate activation of APC $^{\text {Cdh1 }}$ (Listovsky et al. 2000; Bembenek and Yu 2001), although it is not yet clear whether it performs this function in intact cells. Cdc14A has recently been linked with spindle function as well (Kaiser et al. 2002; Mailand et al. 2002). Overexpression of CDC14A leads to prema- ture centrosome splitting and formation of supernumerary mitotic spindles. Inactivation of Cdc14A by siRNA leads to failure of centrosomes to split and to defects in cytokinesis. Thus, although some differences exist between organisms, it appears that the basic mechanism of coupling nuclear division and cytokinesis via Cdc2 inactivation is conserved.

\section{Phosphorylation-independent regulation of $A P C^{C d h 1}$}

The accumulation of A- and B-type cyclins at the $\mathrm{G}_{1} / \mathrm{S}$ transition requires that $\mathrm{APC}^{\mathrm{Cdh} 1}$ be inactivated. This is accomplished not only by Cdh1 phosphorylation, as described above, but also by direct inhibition of APC/C function through a protein called Emil (early mitotic inhibitor) in vertebrate cells and Rcal (regulator of cyclin A) in Drosophila. Xenopus Emil was identified in a twohybrid screen with Skp1 and was found to contain an F-box motif and a putative zinc-binding domain at its C terminus (Reimann et al. 2001a,b). Drosophila Rcal was identified in a screen for mutants that affect the establishment of a $G_{1}$ cell cycle stage during embryogenesis (Dong et al. 1997). Embryos lacking Rcal arrest in $\mathrm{G}_{2}$ of cycle 16 with low levels of cyclin A. Conversely, ectopic expression of Rcal in $G_{1}$ leads to unusually high levels of cyclin A protein and increased cyclin A/Cdk2 activity.

Emil levels vary during early embryonic cell cycles and also in human somatic cells (Reimann et al. 2001a; Hsu et al. 2002). Its level is high during S phase and low during mitosis. In mitotic (but not interphase) Xenopus egg extracts, Emil is destroyed in a proteasome-dependent, but APC-independent, manner (Reimann et al. 2001a). It is possible that this degradation involves the ability of Emil to interact with Skp1. Although assembly of Emil into a functional SCF complex has not been shown, it is conceivable that its incorporation into such a complex could allow its ubiquitination, as has been shown for the F-box protein Skp2 (Wirbelauer et al. 2000). Emil also contains a number of cyclin B/Cdc2 phosphorylation sites, and its phosphorylation during mitosis could potentially trigger its degradation.

The pattern of Emil expression, together with the fact that Rcal mutant embryos arrest in $\mathrm{G}_{2}$, suggested a role for Emil/Rcal in controlling mitotic entry during embryonic cell cycles. Recent experiments indeed suggest that Emil functions as a critical buffer of APC/C activity, allowing mitotic cyclins to accumulate during the $\mathrm{G}_{1} / \mathrm{S}$-phase transition and stay elevated until cells begin mitosis. Two experiments indicated that Emil is central to controlling APC/C activity during mitosis (Reimann et al. 2001a). First, depletion of Emil blocks the ability of Xenopus egg extracts to enter mitosis. Second, overexpression of Emil can block mitotic entry in Xenopus tissue culture cells. These results suggest that Emil can function in both a positive and a negative manner to control mitosis. The first indication that Emil might function directly through the APC/C came with the discovery that Emil can interact with Cdc20 in a two-hybrid assay and that Emil can associate with $\mathrm{APC}^{\mathrm{Cdc2O}}$ and inhibit its activity toward cyclin B in Xenopus ex- 
tracts. This inhibition does not require the F-box motif but does require the putative zinc-binding domain. The timing of Emil expression, together with that of cyclin B accumulation and degradation, suggested that Emil plays a role in buffering APC/C activity during this critical window of time. Thus, Emil allows mitotic cyclin levels to remain elevated when the APC/C is being converted to an activated state via phosphorylation and assembly with Cdc20. Unlike Mad2 (see below), Emi1 functions by binding directly to the substrate-binding region in the $\mathrm{N}$-terminal half of $\mathrm{Cdc} 20$, presumably blocking the Cdc20-substrate interaction. The ability of Emil to block APC ${ }^{\mathrm{Cdc} 20}$ activity has recently been linked to cytostatic factor arrest in Xenopus egg extracts (Reimann and Jackson 2002). Arrest of unfertilized eggs at meiosis II required Emi1, and extracts depleted of Emil destroyed cyclin B and entered mitosis in the absence of fertilization, mimicking the effects of calcium addition.

Although the initial experiments pinpointed the role of Emil in controlling APC ${ }^{\mathrm{Cdc} 2 \mathrm{O}}$ activity, it is now clear that it also controls APC ${ }^{\mathrm{Cdh} 1}$ activity, and this feature allows Emil to control cyclin accumulation both at the $\mathrm{G}_{1} / \mathrm{S}$ boundary and during the onset of mitosis (Fig. 5). In vitro, Emil can inhibit APC ${ }^{\mathrm{Cdh} 1}$ activity through direct association with this complex (Reimann et al. 2001b). At present, it is unclear whether Emil recognizes APC ${ }^{\text {Cdc2O }}$ and $\mathrm{APC}^{\mathrm{Cdh} 1}$ complexes in mechanistically similar ways, although it seems likely that Emil will also block substrate binding to Cdh1. Genetic evidence of its involvement in controlling Cdh1 activity came from analysis of Rcal mutant Drosophila embryos (Grosskortenhaus and Sprenger 2002). Loss of Rcal caused a defect in the accumulation of cyclin A during $G_{2}$ of cycle 16 , leading to a mitotic block. This failure to accumulate cyclin $\mathrm{A}$ is dependent on Cdh1/fzr and is mimicked by overexpression of Cdh $1 / f_{z}$.

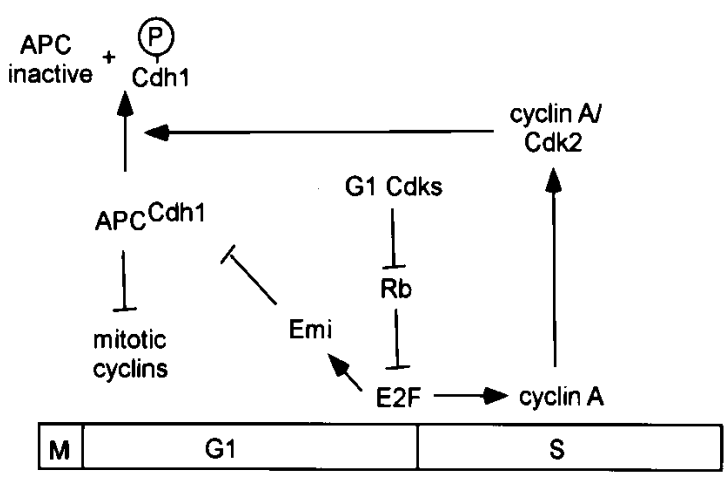

Figure 5. Two mechanisms contribute to inactivation of $\mathrm{APC}^{\mathrm{Cdh} 1}$ at the $\mathrm{G}_{1} / \mathrm{S}$ transition. During $\mathrm{G}_{1}$, low mitotic cyclin levels are maintained by $A C^{C d h 1}$. At the $G_{1} / S$ transition, $G_{1}$ Cdks, which are immune to APC ${ }^{\mathrm{Cdh} 1}$, function to inactivate the retinoblastoma protein $(\mathrm{Rb})$, leading to activation of E2F. There are two outcomes. One is the transcriptional induction of the Cdh1-inhibitor Emil. This leads to partial down-regulation of preformed $\mathrm{APC}^{\mathrm{Cdh} 1}$. Activation of E2F also leads to expression of cyclin A, which activates $\mathrm{Cdk} 2$ and inactivates Cdh1 by phosphorylation.
Evidence suggests that human Emil is also able to inhibit APC ${ }^{\text {Cdh1 }}$. Human Emil accumulates during the $\mathrm{G}_{1} / \mathrm{S}$ transition in synchronized HeLa cells in a manner that parallels cyclin A, and like cyclin A, its accumulation is E2F-dependent (Fig. 5). Moreover, Emil is required to accumulate normal levels of cyclin $\mathrm{A}$ and can overcome a Cdh1-induced $\mathrm{G}_{1}$ arrest when overexpressed (Hsu et al. 2002). The available data indicate that Emil serves as a first line of defense against cyclin A degradation during the $G_{1} / S$ transition. As cyclin $A$ and Emil are transcriptionally induced, Emil can block the rapid degradation of cyclin A by preformed APC ${ }^{\mathrm{Cdh} 1}$ complexes. This then allows the accumulation of cyclin A/Cdk2 activity, which can then function in a positive feedback loop to phosphorylate Cdh1, thereby dissociating it from the APC/C (Fig. 5). In the absence of Cdh1 dephosphorylation (which normally occurs later in the cell cycle; see above), cyclins A and B can be maintained at elevated levels throughout interphase.

Several questions concerning Emil function need to be addressed. First, what is the fate of Emil after Cdh1 phosphorylation during $S$ phase? Emil is stable during this period, but does it remain associated with Cdh1 free of the APC/C? The gel filtration profile of Emil is quite different from that of APC/C complexes, suggesting that it might exist in multiple complexes. Can Emi1 inhibit the various Cdh1 homologs that have been identified (see below)? In addition to preventing substrate binding, does Emil also facilitate inhibitory phosphorylation of Cdh1 by cyclin A/Cdk2? Finally, it is crucial to understand the mechanism by which Emil is destroyed during mitosis, as this represents a critical event for allowing mitosis to proceed.

\section{Spindle assembly checkpoint}

Another mechanism by which the cell inhibits APC/C activity is through the spindle assembly or mitotic checkpoint. This checkpoint ensures the fidelity of chromosome segregation by delaying anaphase onset until all chromosomes are properly attached to the mitotic spindle. Genetic screens in S. cerevisiae were used to identify the key proteins essential for metaphase arrest in the presence of a disrupted mitotic spindle. The MAD1-3 (mitotic arrest defective) and the BUB1-3 (budding uninhibited in benzimidazole) gene products are essential for this process (Hoyt et al. 1991; Li and Murray 1991). Subsequently, Mad1, Mad2, BubR1 (Mad3), Bub1, and Bub3 orthologs were identified in vertebrates (Chen et al. 1996, 1998; Li and Benezra 1996; Taylor and McKeon 1997; Taylor et al. 1998). These vertebrate proteins are found on unattached kinetochores in prometaphase and in the presence of spindle disrupting agents, and are essential for long-term cell viability (Chen et al. 1996; Li and Benezra 1996; Taylor and McKeon 1997; Cahill et al. 1998; Chen et al. 1998; Taylor et al. 1998; Dobles et al. 2000; Michel et al. 2001). Although the Mad and Bub proteins are not essential for viability in budding yeast, their function is nevertheless required during a normal cell cycle, as their deletion results in an increased rate of 
chromosome loss (Hoyt et al. 1991; Li and Murray 1991). Fission yeast checkpoint proteins identified thus far display phenotypes similar to those in budding yeast and, as in metazoans, are found on unattached kinetochores $(\mathrm{He}$ et al. 1997; Bernard et al. 1998; Millband and Hardwick 2002). In contrast, budding yeast Bub2 functions independently of the other Mad and Bub genes in a checkpoint that monitors spindle position (Alexandru et al. 1999; Fesquet et al. 1999; Fraschini et al. 1999; Li 1999; Wang et al. 2000). Fission yeast also possess a Bub2 homolog that shares properties with $S$. cerevisiae Bub2, but whether it monitors spindle position prior to mitotic exit is unclear (Cerutti and Simanis 2000; McCollum and Gould 2001). To date, a Bub2 ortholog has not been identified in vertebrates.

The downstream target of the spindle assembly checkpoint is $\mathrm{APC}^{\mathrm{Cdc} 20}$, whose inhibition prevents sisterchromatid separation by blocking degradation of securin (see above). Much attention has been focused on Mad2's role in the mitotic checkpoint for several reasons. First, Mad2 interacts specifically with Cdc20 in both fission and budding yeasts, and mutations that disrupt the interaction result in loss of the checkpoint response (Hwang et al. 1998; Kim et al. 1998). Second, removal of vertebrate Mad2 using Mad2 antibodies or disrupting one or both $M A D 2$ alleles in mice leads to inappropriate chromosome segregation (Chen et al. 1996; Li and Benezra 1996; Gorbsky et al. 1998; Dobles et al. 2000; Michel et al. 2001). Third, Mad2 is found in a ternary complex containing the APC/C (Li et al. 1997) and Cdc20 in vertebrate cells (Fang et al. 1998b; Kallio et al. 1998; Wassmann and Benezra 1998). Finally, Mad2 cycles on and off unattached kinetochores every $\sim 20 \mathrm{sec}$, consistent with a role as part of a signaling mechanism to propagate the "wait anaphase signal" until all kinetochores are properly attached to the spindle apparatus (Howell et al. 2000).

The molecular mechanism by which Mad2 inhibits $\mathrm{APC}^{\mathrm{Cdc} 20}$ activity is unclear. Mounting evidence suggests that a conformational change in Mad2 may be an important factor for inhibiting $\mathrm{APC}^{\mathrm{Cdc} 20}$. Initial evidence came from Fang and coworkers, who found that recombinant Mad2 protein existed in two states, a monomeric and a tetrameric form (Fang et al. 1998b). Although both forms could bind to Cdc20, only the tetrameric form of Mad2 could inhibit APC ${ }^{\mathrm{Cdc} 20}$ in vitro. The authors proposed that the different oligomeric states observed in vitro might reflect different conformational states of Mad2 that are important for its checkpoint function within cells (Fang et al. 1998b). Further support for a Mad2 conformational change came from the solution structure of Mad2, which showed that the C-terminal flexible region of Mad2 was required for Cdc20-binding (Luo et al. 2000).

This conformational change in Mad2 may arise from its association with Mad1, which is critical for promoting the Mad2-Cdc20 interaction in vivo. First, Mad1 and Mad2 form a tight complex that is constitutively present in cells (Chen et al. 1998; Jin et al. 1998; Chen et al. 1999). Second, Mad1 is needed for Mad2 localization to unattached kinetochores; the Mad2-Cdc20 interaction does not occur in the absence of Mad1 (Chen et al. 1998; Hwang et al. 1998; Hardwick et al. 2000; Luo et al. 2002). Third, Mad1 and Cdc20 bind to a similar region of Mad2, and this region undergoes a similar conformation change upon association with either Mad1 or Cdc20 (Luo et al. 2002). Fourth, Mad1 and Cdc20 can compete for Mad2binding, suggesting that the Mad1-Mad2 and Mad2Cdc20 complexes are mutually exclusive (Sironi et al. 2001, 2002). Finally, the recent crystal structure of the Mad1-Mad2 complex suggests that the C-terminal domain of Mad2 is in a "seatbelt" configuration that must unfold to release Mad1 (Sironi et al. 2002). Together these findings suggest that Mad1 binding to Mad2 and subsequent release from Mad1 induce a conformational change in Mad2 that enables it to bind to unattached kinetochores and Cdc20, culminating in the inactivation of APC ${ }^{\mathrm{Cdc} 20}$ (Sironi et al. 2001, 2002; Luo et al. 2002).

It is not clear how binding of Mad2 might inactivate Cdc20. Mad2 does not appear to prevent substrate binding, as ternary complexes containing Mad2, Cdc20, and APC/C substrates have been observed (Pfleger et al. $2001 \mathrm{~b}$; J.L. Burton and M.J. Solomon, unpubl.), and checkpoint activation does not disrupt Cdc20-substrate interactions in cell extracts (Hilioti et al. 2001). In fact, Mad2 appears to stabilize Cdc20's interaction with substrates (Pfleger et al. 2001b), leading to the possibility that Mad2 might inhibit APC ${ }^{\mathrm{Cdc} 20}$ activity by trapping bound substrate or even by preventing release of ubiquitinated products. The ability of Mad2 to inhibit Cdc20 is not absolute, because cyclin A is still degraded by $\mathrm{APC}^{\mathrm{Cdc} 20}$ in checkpoint-arrested cells (Geley et al. 2001).

Recently, the role of BubR1/Mad3 in the spindle assembly checkpoint has gained some attention (Sudakin et al. 2001; Tang et al. 2001b). BubR1/Mad3, like Mad2, can interact directly with Cdc20 (Hardwick et al. 2000; $\mathrm{Wu}$ et al. 2000; Tang et al. 2001b). In addition to its localization on unattached kinetochores (Taylor et al. 1998), BubR1 binds to CENP-E, a kinetochore-associated motor protein whose function is required for chromosome congression at the metaphase plate in vertebrates (Schaar et al. 1997; Wood et al. 1997; Chan et al. 1998; Yao et al. 2000). Depletion of CENP-E strongly stimulates the checkpoint response (Yao et al. 2000). Thus, BubR1 is in a prime location for monitoring the link between microtubule attachment/tension at the kinetochore and chromosome movement (Schaar et al. 1997; Wood et al. 1997; Chan et al. 1998; Yao et al. 2000).

Two recent papers have biochemically verified the importance of BubR1 in the checkpoint response. Sudakin and colleagues purified an APC ${ }^{\mathrm{Cdc} 20}$ inhibitory complex from HeLa cells that they termed MCC for mitotic checkpoint complex. This complex contained BubR1, Bub3, Cdc20, and Mad2 in near equal stoichiometry (Sudakin et al. 2001). Interestingly, the MCC was 3000fold more potent than recombinant Mad2 in $\mathrm{APC}^{\mathrm{Cdc} 20}$ inhibition (Sudakin et al. 2001). Tang et al. (2001b) obtained similar results, showing that a BubR1-containing complex was more potent than recombinant Mad2 at $\mathrm{APC}^{\mathrm{Cdc} 20}$ inhibition, although their complex only con- 
tained BubR1 and Bub3, but not Cdc20 or Mad2. The reason for this discrepancy is unclear and may reflect differences in purification strategies. Fang (2002) has also shown that Mad2 and BubR1 enhance each other's binding to Cdc20, consistent with the existence of a Mad2Cdc20-BubR1 complex. Studies in both fission and budding yeast are also consistent with the possibility of a Mad2-Cdc20-Mad3(BubR1)-Bub3 complex (Hardwick et al. 2000; Millband and Hardwick 2002), although it has not yet been identified biochemically. It is not clear if what has been learned about the ability of $\operatorname{Mad} 2$ to inhibit $\mathrm{APC}^{\mathrm{Cdc} 20}$ will also apply to the MCC complex. Intriguingly, the MCC complex exists in interphase cells, but neither the interphase nor the mitotic forms of the MCC can inhibit the interphase form of the APC/C, raising the possibility that mitotic phosphorylation of the APC/C may render it susceptible to inhibition by the MCC (Sudakin et al. 2001).

A protein homologous to Mad2 known variously as Mad2L2, Mad2B, and Rev7 has been identified in both Xenopus and humans (Cahill et al. 1999; Chen and Fang 2001; Pfleger et al. 2001b). Mad2L2/Mad2B binds Cdh1 and preferentially inhibits $\mathrm{APC}^{\mathrm{Cdh} 1}$ activity in vitro (Chen and Fang 2001; Pfleger et al. 2001b). Injection of Mad2L2/Mad2B into Xenopus embryos resulted in a cell cycle arrest later in the developmental program at the onset of somatic cell cycles when Cdh1 activity is first required (Pfleger et al. 2001b). These findings raise the intriguing possibility that, like $\mathrm{APC}^{\mathrm{Cdc} 20}, \mathrm{APC}^{\mathrm{Cdh} 1}$ activity is also under checkpoint regulation. However, unlike Mad2, Mad2L2/Mad2B was not found on unattached kinetochores and did not associate with Mad1 (Chen and Fang 2001), suggesting that it does not function in the spindle assembly checkpoint. It may play a role in a later cell cycle checkpoint or perhaps even in regulating the degradation of proteins in differentiated cells (Chen and Fang 2001). Future studies will be required to understand the physiological significance of this APC/C inhibition.

Many questions remain regarding the spindle assembly checkpoint and APC/C inhibition. How does the unattached kinetochore (or lack of kinetochore tension) signal the checkpoint proteins to inhibit $\mathrm{APC}^{\mathrm{Cdc} 20}$, and how are these checkpoint complexes assembled? What is the molecular mechanism for $\mathrm{APC}^{\mathrm{Cdc} 20}$ inhibition by the checkpoint proteins? How is the checkpoint signal extinguished once the spindle is properly assembled? Is $\mathrm{APC}^{\mathrm{Cdh} 1}$ activity also regulated by a cell cycle checkpoint? Answers to these questions (and others) will not only satisfy our innate curiosity, but also prove useful in the fight against cancer.

\section{Roles for the APC/C outside the cell cycle}

Although it is clear that the APC/C plays major roles in the cell division cycle, its roles in non-cell-cycle functions are only beginning to be recognized. The first example of degradation of a non-cell-cycle control protein came with the identification of SnoN as an APC/C substrate (Stroschein et al. 2001; Wan et al. 2001). SnoN is a negative regulator of TGF $\beta$ signaling. In response to
TGF $\beta$, Smads 2 and 3 translocate to the nucleus and initiate the degradation of SnoN. SnoN contains a destruction box and is ubiquitinated in vitro by $\mathrm{APC}^{\mathrm{Cdh} 1}$. In tissue culture cells, SnoN degradation requires an intact destruction box and the interaction between Smad3 and SnoN (Stroschein et al. 2001). One possible mechanism is that association of Smad3 with SnoN reveals an otherwise protected destruction box. Regardless of the mechanism, these data provide a tantalizing first glimpse into how the APC/C might be involved in the control of diverse processes.

\section{Multiple Cdh1 homologs in vertebrates}

What might be other functions of the APC/C outside the cell cycle? Clues to this question came from an analysis of $\mathrm{APC} / \mathrm{C}$ expression in nondividing tissues. Whereas $\mathrm{Cdc} 20$ is restricted to cycling lineages, $\mathrm{Cdh} 1$ and core APC/C subunits are present in postmitotic tissues including neurons (Gieffers et al. 1999). Moreover, neuronal APC/C complexes are active, leading to the proposition that the APC/C catalyzes ubiquitination of as-yetunknown targets. Mice that are conditionally mutant for Cdh1 might provide a means to address the function of Cdh1 in the brain. Recent work has also revealed the existence of multiple Cdh1 homologs in vertebrates, most notably in chickens, which contain four Cdh1 homologs (Wan and Kirschner 2001). These genes display distinct patterns of expression in vivo and different substrate specificities in vitro. For example, Cdh1-C has a broad substrate specificity, catalyzing ubiquitination of a wide array of APC/C substrates. In contrast, Cdh1-A and Cdh1-B ubiquitinate only Plk1 and Nek1, respectively. The basis of this specificity is not clear. Little is known about the roles of these Cdh1 homologs or how many additional Cdh1 homologs may be present in vertebrates.

\section{A role for the $A P C / C$ in asymmetric cell division}

Recent studies implicate the APC/C, Cdc20, and separase in controlling the establishment of cell polarity and asymmetric cell division during $C$. elegans embryogenesis. Polarity is established in the single-cell embryo through selective localization of polarity (PAR) proteins at the anterior and posterior poles (Knoblich 2001). These signals are required for an asymmetric first cell division and appear to contribute to asymmetric control in subsequent divisions. The APC/C also contributes to asymmetry in this system (Rappleye et al. 2002). Unlike wild-type embryos, pod (polarity and osmotic defective) mutants undergo a symmetrical first zygotic division and orient both sets of spindles perpendicular to the anterior-posterior axis during a second synchronous zygotic division (Fig. 6). pod function is required between fertilization and meiosis I. pod mutants display inappropriate localization of PAR proteins, indicating a defect in the pathway that specifies polarity. Five complementation groups defined by pod-3, pod-4, pod-5, pod-6, and emb-30 map to APC1, APC8/Cdc23, APC3/Cdc27, 


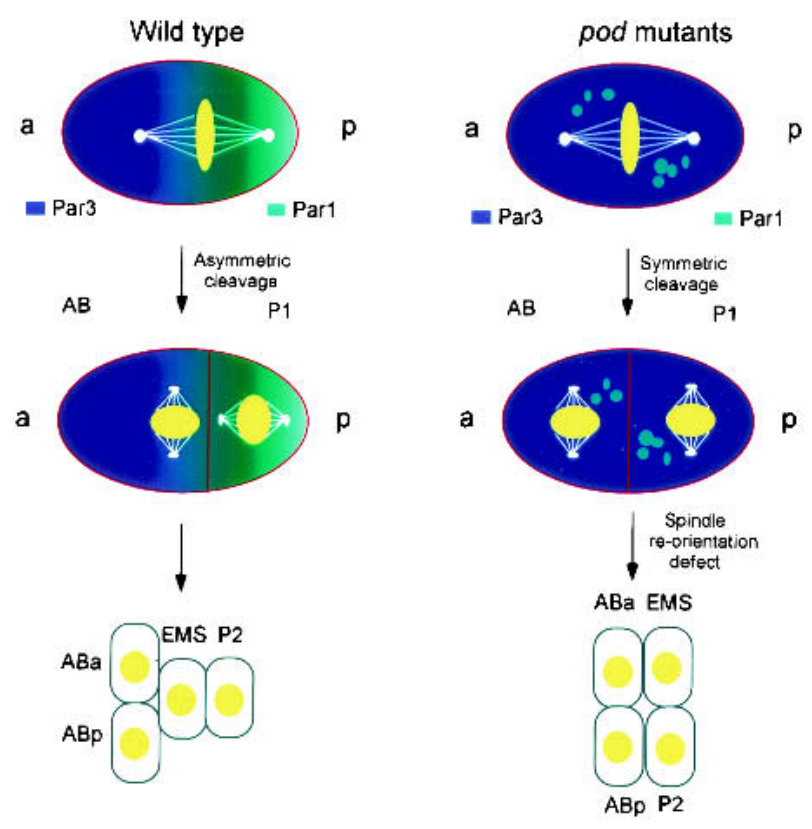

Figure 6. A role for the $\mathrm{APC} / \mathrm{C}$ in cell polarity during Caenorhabditis elegans embryonic development. C. elegans onecell embryos undergo a stereotypic asymmetric cell division to create a large $\mathrm{AB}$ cell and a small $\mathrm{P} 1$ cell. This division is followed by rotation of the P1 nucleus to generate a longitudinal mitosis in the second cleavage and a transverse mitosis in the $\mathrm{AB}$ cell second cleavage. These events depend on polarity signals governed by Par3 and Par1, which localize anteriorly and posteriorly, respectively. In pod mutants, polarity in the onecell embryo is lost, and the spindle is unable to maintain close association with the posterior cortex, leading to symmetric cell division. In addition, in the second division, the P1 nucleus is unable to rotate and undergoes a synchronous transverse mitosis with the AB cell. Par3 and Parl are localized inappropriately in pod mutants.

APC6/Cdc16, and APC4. Such pod mutants appear to be partial loss-of-function alleles as severe mutations of these genes cause arrest at metaphase of meiosis I (Golden et al. 2000). One potential role for the APC/C appears to be in bringing the paternal pronucleus into close contact with the posterior cortex. In pod-3 mutants, the paternal pronucleus fails to cling to the posterior cortex and meets the maternal pronucleus in the cell center, resulting in symmetric cleavage. This function appears to involve both Cdc20 and separase. Partial loss of $c d c 20$ function leads to a symmetric first cleavage and mislocalization of polarity components. One potential target of the APC/C in polarity may be separase, because depletion of separase also leads to polarity defects. However, the phenotypes of APC/C mutants and of reduction in separase levels by RNAi are subtly different, suggesting that additional targets may be involved. It will be important to determine whether the APC/C is involved in establishing polarity in other settings.

Although the APC/C is clearly involved in cell polarity decisions, other events during the first and second cell divisions in C. elegans are controlled by SCF-type ubiquitin ligases. Evidence for this comes from an analy- sis of the Nedd8/Cul3 pathway (Kurz et al. 2002). As mentioned above, all known cullin homologs are activated by conjugation to the ubiquitin-like protein Nedd8. In C. elegans, temperature-sensitive mutations in the Nedd8 activating enzyme (rfl-1) cause multiple defects in the early embryo, including misorientation of mitotic spindles, the formation of ectopic cleavage furrows, and persistent displacement of nuclei toward the cell cortex. Many of these phenotypes are mimicked by RNAi-mediated ablation of cul-3, suggesting that neddylation of Cul-3 is critical for proper early divisions. The molecular makeup of cul-3-based ubiquitin ligases has not yet been defined, and it is presently unclear whether these defects reflect a single Cul-3-based ubiquitin ligase or multiple independent Cul-3 complexes. The identification of targets of cul-3 will be required to clarify how these defects in cytokinesis come about.

\section{Conclusion}

The last decade has seen substantial strides in our understanding of cell cycle control and the functions of the $\mathrm{APC} / \mathrm{C}$ in this process. We now have a clear view of the role played by the APC/C in catalyzing distinct cell cycle transitions, and we have a good understanding of the components of the APC/C. What does the future hold? Clearly, a major deficit exists in our understanding of precisely how the APC/C works and why it needs so many subunits. To understand these issues, structural information will need to be integrated with functional analysis of individual subunits. Also, structural analysis of motifs involved in substrate recognition may make it possible not only to understand how substrates are selected but also to identify additional substrates. Furthermore, we have only scratched the surface with respect to understanding non-cell-cycle roles of the APC/C. Additional Cdh1 homologs have roles either in cell division or non-cell-cycle functions, and the elucidation of these functions will likely require reverse genetics in vertebrate systems. Finally, we have only a rudimentary understanding of how Cdh1 regulation is linked with the mitotic exit pathway. Genetic and biochemical studies will be required to elaborate the signaling pathway responsible for dephosphorylation of Cdh1 as animal cells exit mitosis.

\section{Acknowledgments}

Support for APC-related work in our laboratories is provided by NIH grant no. GM48330 to M.J.S., by NIH grant no. AG11085 to J.W.H., and by the Human Frontiers Science Program to J.W.H.

\section{Note added in proof}

We described evidence indicating that Pds1 and Clb5 are the sole essential substrates of $\mathrm{APC}^{\mathrm{Cdc} 20}$ required for exit from mitosis. Clb5 is thought to inhibit mitotic exit by phosphorylation of Cdh1, thereby blocking destruction of mitotic cyclins such as Clb2. A very recent paper questions the central role of Clb5 destruction in mitotic exit (Wasch and Cross 2002). This paper 
reports that certain aspects of mitotic exit, including spindle disassembly, require Clb2 degradation, but these processes can occur in the presence of a nondegradable form of Clb5. These provocative data reinforce the notion that distinct mitotic events are differently sensitive to the levels of particular Cdk family members.

\section{References}

Agarwal, R. and Cohen-Fix, O. 2002. Phosphorylation of the mitotic regulator Pds1/securin by Cdc28 is required for efficient nuclear localization of Esp1/separase. Genes \& Dev. 16: 1371-1382.

Alexandru, G., Zachariae, W., Schleiffer, A., and Nasmyth, K. 1999. Sister chromatid separation and chromosome re-duplication are regulated by different mechanisms in response to spindle damage. $E M B O J$. 18: 2707-2721.

Alexandru, G., Uhlmann, F., Mechtler, K., Poupart, M.A., and Nasmyth, K. 2001. Phosphorylation of the cohesin subunit Scc1 by Polo/Cdc5 kinase regulates sister chromatid separation in yeast. Cell 105: 459-472.

Amon, A. 1997. Regulation of B-type cyclin proteolysis by Cdc28-associated kinases in budding yeast. $E M B O ~ J . ~ 16:$ 2693-2702.

Amon, A., Irniger, S., and Nasmyth, K. 1994. Closing the cell cycle circle in yeast: $G_{2}$ cyclin proteolysis initiated at mitosis persists until the activation of $G_{1}$ cyclins in the next cycle. Cell 77: 1037-1050.

Anghileri, P., Branduardi, P., Sternieri, F., Monti, P., Visintin, R., Bevilacqua, A., Alberghina, L., Martegani, E., and Baroni, M.D. 1999. Chromosome separation and exit from mitosis in budding yeast: Dependence on growth revealed by cAMPmediated inhibition. Exp. Cell Res. 250: 510-523.

Aristarkhov, A., Eytan, E., Moghe, A., Admon, A., Hershko, A., and Ruderman, J.V. 1996. E2-C, a cyclin-selective ubiquitin carrier protein required for the destruction of mitotic cyclins. Proc. Natl. Acad. Sci. 93: 4294-4299.

Au, S.W., Leng, X., Harper, J.W., and Barford, D. 2002. Implications for the ubiquitination reaction of the anaphase-promoting complex from the crystal structure of the Doc1/ Apc10 subunit. J. Mol. Biol. 316: 955-968.

Bai, C., Sen, P., Mathias, N., Hofmann, K., Goebl, M., Harper, J.W., and Elledge, S.J. 1996. SKP1 connects cell cycle regulation to the ubiquitin proteolysis machinery through a novel motif, the F-box. Cell 86: 263-274.

Balasubramanian, M.K., McCollum, D., and Surana, U. 2000. Tying the knot: Linking cytokinesis to the nuclear cycle. $J$. Cell Sci. 113: 1503-1513.

Bardin, A.J. and Amon, A. 2001. MEN and SIN: What's the difference? Nat. Rev. Mol. Cell. Biol. 2: 815-826.

Bardin, A.J., Visintin, R., and Amon, A. 2000. A mechanism for coupling exit from mitosis to partitioning of the nucleus. Cell 102: 21-31.

Barral, Y., Jentsch, S., and Mann, C. 1995. $G_{1}$ cyclin turnover and nutrient uptake are controlled by a common pathway in yeast. Genes \& Dev. 9: 399-409.

Baumer, M., Braus, G.H., and Irniger, S. 2000. Two different modes of cyclin Clb2 proteolysis during mitosis in Saccharomyces cerevisiae. FEBS Lett. 468: 142-148.

Bembenek, J. and Yu, H. 2001. Regulation of the anaphase-promoting complex by the dual specificity phosphatase human Cdc14a. J. Biol. Chem. 276: 48237-48242.

Bentley, A.M., Williams, B.C., Goldberg, M.L., and Andres, A.J. 2002. Phenotypic characterization of Drosophila ida mutants: Defining the role of APC5 in cell cycle progression. J.
Cell Sci. 115: 949-961.

Bernard, P., Hardwick, K., and Javerzat, J.P. 1998. Fission yeast Bub1 is a mitotic centromere protein essential for the spindle checkpoint and the preservation of correct ploidy through mitosis. J. Cell Biol. 143: 1775-1787.

Blanco, M.A., Sanchez-Diaz, A., Prada, J.M.d., and Moreno, S. 2000. APC ${ }^{\text {ste9/srwl }}$ promotes degradation of mitotic cyclins in $\mathrm{G}_{1}$ and is inhibited by cdc2 phosphorylation. EMBO $J$. 19: 3945-3955.

Bolte, M., Steigemann, P., Braus, G.H., and Irniger, S. 2002. Inhibition of APC-mediated proteolysis by the meiosis-specific protein kinase Ime2. Proc. Nat1. Acad. Sci. 99: 43854390.

Burton, J.L. and Solomon, M.J. 2000. Hsllp, a Swelp inhibitor, is degraded via the anaphase-promoting complex. Mol. Cell. Biol. 20: 4614-4625.

- 2001. D box and KEN box motifs in budding yeast Hsllp are required for APC-mediated degradation and direct binding to Cdc20p and Cdh1p. Genes \& Dev. 15: 2381-2395.

Cahill, D.P., Lengauer, C., Yu, J., Riggins, G.J., Willson, J.K., Markowitz, S.D., Kinzler, K.W., and Vogelstein, B. 1998. Mutations of mitotic checkpoint genes in human cancers. Nature 392: 300-303.

Cahill, D.P., da Costa, L.T., Carson-Walter, E.B., Kinzler, K.W., Vogelstein, B., and Lengauer, C. 1999. Characterization of $M A D 2 B$ and other mitotic spindle checkpoint genes. Genomics 58: 181-187.

Castro, A., Arlot-Bonnemains, Y., Vigneron, S., Labbé, J.C., Prigent, C., and Lorca, T. 2002. APC/Fizzy-related targets aurora-A kinase for proteolysis. EMBO Rep. 3: 457-462.

Cerutti, L. and Simanis, V. 2000. Controlling the end of the cell cycle. Curr. Opin. Genet. Dev. 10: 65-69.

Chan, G.K., Schaar, B.T., and Yen, T.J. 1998. Characterization of the kinetochore binding domain of CENP-E reveals interactions with the kinetochore proteins CENP-F and hBUBR1. J. Cell Biol. 143: 49-63.

Charles, J.F., Jaspersen, S.L., Tinker-Kulberg, R.L., Hwang, L., Szidon, A., and Morgan, D.O. 1998. The Polo-related kinase Cdc5 activates and is destroyed by the mitotic cyclin destruction machinery in S. cerevisiae. Curr. Biol. 8: 497-507.

Chen, J. and Fang, G. 2001. MAD2B is an inhibitor of the anaphase-promoting complex. Genes \& Dev. 15: 1765-1770.

Chen, R.H., Waters, J.C., Salmon, E.D., and Murray, A.W. 1996. Association of spindle assembly checkpoint component XMAD2 with unattached kinetochores. Science 274: 242 246

Chen, R.H., Shevchenko, A., Mann, M., and Murray, A.W. 1998. Spindle checkpoint protein Xmad1 recruits Xmad2 to unattached kinetochores. J. Cell Biol. 143: 283-295.

Chen, R.H., Brady, D.M., Smith, D., Murray, A.W., and Hardwick, K.G. 1999. The spindle checkpoint of budding yeast depends on a tight complex between the Mad1 and Mad2 proteins. Mol. Biol. Cell 10: 2607-2618.

Cheng, L., Collyer, T., and Hardy, C.F. 1999. Cell cycle regulation of DNA replication initiator factor Dbf4p. Mol. Cell. Biol. 19: 4270-4278.

Ciosk, R., Zachariae, W., Michaelis, C., Shevchenko, A., Mann, M., and Nasmyth, K. 1998. An ESP1/PDS1 complex regulates loss of sister chromatid cohesion at the metaphase to anaphase transition in yeast. Cell 93: 1067-1076.

Ciosk, R., Shirayama, M., Shevchenko, A., Tanaka, T., Toth, A., Shevchenko, A., and Nasmyth, K. 2000. Cohesin's binding to chromosomes depends on a separate complex consisting of Scc2 and Scc4 proteins. Mol. Cell 5: 243-254.

Clute, P. and Pines, J. 1999. Temporal and spatial control of cyclin B1 destruction in metaphase. Nat. Cell Biol. 1: 82-87. 
Cohen-Fix, O., Peters, J.M., Kirschner, M.W., and Koshland, D. 1996. Anaphase initiation in Saccharomyces cerevisiae is controlled by the APC-dependent degradation of the anaphase inhibitor Pds1p. Genes \& Dev. 10: 3081-3093.

Cooper, K.F., Mallory, M.J., Egeland, D.B., Jarnik, M., and Strich, R. 2000. Amalp is a meiosis-specific regulator of the anaphase promoting complex/cyclosome in yeast. Proc. Nat1. Acad. Sci. 97: 14548-14553.

Cueille, N., Salimova, E., Esteban, V., Blanco, M., Moreno, S., Bueno, A., and Simanis, V. 2001. Flp1, a fission yeast orthologue of the $S$. cerevisiae CDC14 gene, is not required for cyclin degradation or rum $1 \mathrm{p}$ stabilisation at the end of mitosis. J. Cell Sci. 114: 2649-2664.

Dahmann, C., Diffley, J.F., and Nasmyth, K.A. 1995. S-phasepromoting cyclin-dependent kinases prevent re-replication by inhibiting the transition of replication origins to a prereplicative state. Curr. Biol. 5: 1257-1269.

Dawson, I.A., Roth, S., Akam, M., and Artavanis-Tsakonas, S. 1993. Mutations of the fizzy locus cause metaphase arrest in Drosophila melanogaster embryos. Development 117: 359376.

Descombes, P. and Nigg, E.A. 1998. The Polo-like kinase Plx1 is required for $\mathrm{M}$ phase exit and destruction of mitotic regulators in Xenopus egg extracts. EMBO J. 17: 1328-1335.

Deshaies, RJ. 1999. SCF and cullin/RING H2-based ubiquitin ligases. Annu. Rev. Cell Dev. Biol. 15: 435-467.

Deshaies R.J. and Ferrell, J.E., Jr. 2001. Multisite phosphorylation and the countdown to S phase. Cell 107: 819-822.

Deshaies, R.J., Chau, V., and Kirschner, M. 1995. Ubiquitination of the $\mathrm{G}_{1}$ cyclin $C \ln 2 \mathrm{p}$ by a $\mathrm{Cdc} 34 \mathrm{p}$-dependent pathway. EMBO J. 14: 303-312.

Diffley, J.F. 1996. Once and only once upon a time: Specifying and regulating origins of DNA replication in eukaryotic cells. Genes \& Dev. 10: 2819-2830.

2001. DNA replication: Building the perfect switch. Curr. Biol. 11: R367-R370.

Diffley, J.F. and Labib, K. 2002. The chromosome replication cycle. J. Cell Sci. 115: 869-872.

Dobles, M., Liberal, V., Scott, M.L., Benezra, R., and Sorger, P.K. 2000. Chromosome missegregation and apoptosis in mice lacking the mitotic checkpoint protein Mad2. Cell 101: 635645.

Dong, X., Zavitz, K.H., Thomas, B.J., Lin, M., Campbell, S., and Zipursky, S.L. 1997. Control of $\mathrm{G}_{1}$ in the developing Drosophila eye: rcal regulates cyclin A. Genes \& Dev. 11: 94 105.

Drury, L.S., Perkins, G., and Diffley, J.F. 1997. The Cdc4/34/53 pathway targets Cdc6p for proteolysis in budding yeast. EMBO J. 16: 5966-5976.

- 2000. The cyclin-dependent kinase Cdc28p regulates distinct modes of Cdc6p proteolysis during the budding yeast cell cycle. Curr. Biol. 10: 231-240.

Evans, T., Rosenthal, E.T., Youngblom, J., Distel, D., and Hunt, T. 1983. Cyclin: A protein specified by maternal mRNA in sea urchin eggs that is destroyed at each cleavage division. Cell 33: 389-396.

Fang, G. 2002. Checkpoint protein BubR1 acts synergistically with Mad2 to inhibit anaphase-promoting complex. Mol. Biol. Cell 13: 755-766.

Fang, G., Yu, H., and Kirschner, M.W. 1998a. Direct binding of CDC20 protein family members activates the anaphase-promoting complex in mitosis and $\mathrm{G}_{1}$. Mol. Cell 2: 163-171.

. 1998b. The checkpoint protein MAD2 and the mitotic regulator $\mathrm{CDC} 20$ form a ternary complex with the anaphasepromoting complex to control anaphase initiation. Genes \& Dev. 12: 1871-1883.
Feldman, R.M., Correll, C.C., Kaplan, K.B., and Deshaies, R.J. 1997. A complex of Cdc4p, Skplp, and Cdc53p/cullin catalyzes ubiquitination of the phosphorylated CDK inhibitor Sic1p. Cell 91: 221-230.

Félix, M.A., Labbé, J.C., Dorée, M., Hunt, T., and Karsenti, E. 1990. Triggering of cyclin degradation in interphase extracts of amphibian eggs by cdc2 kinase. Nature 346: 379-382.

Ferreira, M.F., Santocanale, C., Drury, L.S., and Diffley, J.F. 2000. Dbf4p, an essential S phase-promoting factor, is targeted for degradation by the anaphase-promoting complex. Mol. Cell. Biol. 20: 242-248.

Fesquet, D., Fitzpatrick, P.J., Johnson, A.L., Kramer, K.M., Toyn, J.H., and Johnston, L.H. 1999. A Bub2p-dependent spindle checkpoint pathway regulates the Dbf2p kinase in budding yeast. EMBO J. 18: 2424-2434.

Fraschini, R., Formenti, E., Lucchini, G., and Piatti, S. 1999. Budding yeast Bub2 is localized at spindle pole bodies and activates the mitotic checkpoint via a different pathway from Mad2. J. Cell Biol. 145: 979-991.

Funabiki, H., Yamano, H., Kumada, K., Nagano, K., Hunt, T., and Yanagida, M. 1996. Cut2 proteolysis required for sisterchromatid separation in fission yeast. Nature 381: 438-441.

Furuta, T., Tuck, S., Kirschner, J., Koch, B., Auty, R., Kitagawa, R., Rose, A.M., and Greenstein, D. 2000. EMB-30: An APC4 homologue required for metaphase-to-anaphase transitions during meiosis and mitosis in Caenorhabditis elegans. Mol. Biol. Cell 11: 1401-1419.

Furuya, K., Takahashi, K., and Yanagida, M. 1998. Faithful anaphase is ensured by Mis4, a sister chromatid cohesion molecule required in $S$ phase and not destroyed in $G_{1}$ phase. Genes \& Dev. 12: 3408-3418.

Geley, S., Kramer, E., Gieffers, C., Gannon, J., Peters, J.M., and Hunt, T. 2001. Anaphase-promoting complex/cyclosome-dependent proteolysis of human cyclin A starts at the beginning of mitosis and is not subject to the spindle assembly checkpoint. J. Cell Biol. 153: 137-148.

Gieffers, C., Peters, B.H., Kramer, E.R., Dotti, C.G., and Peters, J.M. 1999. Expression of the CDH1-associated form of the anaphase-promoting complex in postmitotic neurons. Proc. Nat1. Acad. Sci. 96: 11317-11322.

Gieffers, C., Dube, P., Harris, J.R., Stark, H., and Peters, J.M. 2001. Three-dimensional structure of the anaphase-promoting complex. Mol. Cell 7: 907-913.

Glotzer, M., Murray, A.W., and Kirschner, M.W. 1991. Cyclin is degraded by the ubiquitin pathway. Nature 349: 132-138.

Gmachl, M., Gieffers, C., Podtelejnikov, A.V., Mann, M., and Peters, J.M. 2000. The RING-H2 finger protein APC11 and the E2 enzyme UBC4 are sufficient to ubiquitinate substrates of the anaphase-promoting complex. Proc. Natl. Acad. Sci. 97: 8973-8978.

Golan, A., Yudkovsky, Y., and Hershko, A. 2002. The cyclinubiquitin ligase activity of cyclosome/APC is jointly activated by protein kinases Cdk1-cyclin B and Plk. J. Biol. Chem. 277: 15552-15557.

Golden, A., Sadler, P.L., Wallenfang, M.R., Schumacher, J.M., Hamill, D.R., Bates, G., Bowerman, B., Seydoux, G., and Shakes, D.C. 2000. Metaphase to anaphase (mat) transitiondefective mutants in Caenorhabditis elegans. J. Cell Biol. 151: 1469-1482.

Gorbsky, G.J., Chen, R.H., and Murray, A.W. 1998. Microinjection of antibody to Mad2 protein into mammalian cells in mitosis induces premature anaphase. J. Cell Biol. 141: 1193-1205.

Gordon, D.M. and Roof, D.M. 2001. Degradation of the kinesin Kiplp at anaphase onset is mediated by the anaphase-promoting complex and Cdc20p. Proc. Natl. Acad. Sci. 98: $12515-12520$. 
Grossberger, R., Gieffers, C., Zachariae, W., Podtelejnikov, A.V., Schleiffer, A., Nasmyth, K., Mann, M., and Peters, J.M. 1999. Characterization of the DOC1/APC10 subunit of the yeast and the human anaphase-promoting complex. J. Biol. Chem. 274: 14500-14507.

Grosskortenhaus, R. and Sprenger, F. 2002. Rcal inhibits APCCdh1(Fzr) and is required to prevent cyclin degradation in $\mathrm{G}_{2}$. Dev. Cell 2: 29-40.

Guacci, V., Koshland, D., and Strunnikov, A. 1997. A direct link between sister chromatid cohesion and chromosome condensation revealed through the analysis of $M C D 1$ in $S$. cerevisiae. Cell 91: 47-57.

Hames, R.S., Wattam, S.L., Yamano, H., Bacchieri, R., and Fry, A.M. 2001. APC/C-mediated destruction of the centrosomal kinase Nek2A occurs in early mitosis and depends upon a cyclin A-type D-box. EMBO J. 20: 7117-7127.

Hardwick, K.G., Johnston, R.C., Smith, D.L., and Murray, A.W. 2000. MAD3 encodes a novel component of the spindle checkpoint which interacts with Bub3p, Cdc20p, and Mad2p. J. Cell Biol. 148: 871-882.

Harper, J.W. 2002. A phosphorylation-driven ubiquitination switch for cell-cycle control.Trends Cell Biol. 12: 104107.

Hauf, S., Waizenegger, I.C., and Peters, J.M. 2001. Cohesin cleavage by separase required for anaphase and cytokinesis in human cells. Science 293: 1320-1323.

He, X., Patterson, T.E., and Sazer, S. 1997. The Schizosaccharomyces pombe spindle checkpoint protein mad2p blocks anaphase and genetically interacts with the anaphase-promoting complex. Proc. Natl. Acad. Sci. 94: 7965-7970.

Hendrickson, C., Meyn III, M.A., Morabito, L., and Holloway, S.L. 2001. The KEN box regulates Clb2 proteolysis in $\mathrm{G}_{1}$ and at the metaphase-to-anaphase transition. Curr. Biol. 11: $1781-1787$.

Hershko, A. and Ciechanover, A. 1998. The ubiquitin system. Annu. Rev. Biochem. 67: 425-479.

Hershko, A., Ganoth, D., Sudakin, V., Dahan, A., Cohen, L.H., Luca, F.C., Ruderman, J.V., and Eytan, E. 1994. Components of a system that ligates cyclin to ubiquitin and their regulation by the protein kinase cdc2. J. Biol. Chem. 269: 49404946.

Hildebrandt, E.R. and Hoyt, M.A. 2001. Cell cycle-dependent degradation of the Saccharomyces cerevisiae spindle motor Cin8p requires $\mathrm{APC}^{\mathrm{Cdh} 1}$ and a bipartite destruction sequence. Mol. Biol. Cell 12: 3402-3416.

Hilioti, Z., Chung, Y.S., Mochizuki, Y., Hardy, C.F., and CohenFix, O. 2001. The anaphase inhibitor Pds1 binds to the APC/ $\mathrm{C}$-associated protein Cdc20 in a destruction box-dependent manner. Curr. Biol. 11: 1347-1352.

Holloway, S.L., Glotzer, M., King, R.W., and Murray, A.W. 1993. Anaphase is initiated by proteolysis rather than by the inactivation of maturation-promoting factor. Cell 73: 13931402.

Howell, B.J., Hoffman, D.B., Fang, G., Murray, A.W., and Salmon, E.D. 2000. Visualization of Mad2 dynamics at kinetochores, along spindle fibers, and at spindle poles in living cells. J. Cell Biol. 150: 1233-1250.

Hoyt, M.A. and Geiser, J.R. 1996. Genetic analysis of the mitotic spindle. Annu. Rev. Genet. 30: 7-33.

Hoyt, M.A., Totis, L., and Roberts, B.T. 1991. S. cerevisiae genes required for cell cycle arrest in response to loss of microtubule function. Cell 66: 507-517.

Hsiung, Y.G., Chang, H.C., Pellequer, J.L., La Valle, R., Lanker, S., and Wittenberg, C. 2001. F-box protein Grrl interacts with phosphorylated targets via the cationic surface of its leucine-rich repeat. Mol. Cell. Biol. 21: 2506-2520.
Hsu, J.Y., Reimann, J.D., Sorensen, C.S., Lukas, J., and Jackson, P.K. 2002. E2F-dependent accumulation of hEmil regulates S phase entry by inhibiting APC ${ }^{\mathrm{Cdh} 1}$. Nat. Cell Biol. 4: 358 366.

Huang, J. and Raff, J.W. 1999. The disappearance of cyclin B at the end of mitosis is regulated spatially in Drosophila cells. EMBO I. 18: 2184-2195.

Huang, J.N., Park, I., Ellingson, E., Littlepage, L.E., and Pellman, D. 2001. Activity of the APC ${ }^{\text {Cdhl } 1}$ form of the anaphase-promoting complex persists until S phase and prevents the premature expression of Cdc20p. J. Cell Biol. 154: 85-94.

Hwang, L.H. and Murray, A.W. 1997. A novel yeast screen for mitotic arrest mutants identifies DOC1, a new gene involved in cyclin proteolysis. Mol. Biol. Cell 8: 1877-1887.

Hwang, L.H., Lau, L.F., Smith, D.L., Mistrot, C.A., Hardwick, K.G., Hwang, E.S., Amon, A., and Murray, A.W. 1998. Budding yeast Cdc20: A target of the spindle checkpoint. Science 279: $1041-1044$

Irniger, S. and Nasmyth, K. 1997. The anaphase-promoting complex is required in $\mathrm{G}_{1}$ arrested yeast cells to inhibit B-type cyclin accumulation and to prevent uncontrolled entry into S-phase. J. Cell Sci. 110: 1523-1531.

Irniger, S., Piatti, S., Michaelis, C., and Nasmyth, K. 1995. Genes involved in sister chromatid separation are needed for B-type cyclin proteolysis in budding yeast. Cell 81: 269278.

Jacobs, H.W., Keidel, E., and Lehner, C.F. 2001. A complex degradation signal in cyclin $A$ required for $G_{1}$ arrest, and a Cterminal region for mitosis. EMBO J. 20: 2376-2386.

Jaspersen, S.L., Charles, J.F., and Morgan, D.O. 1999. Inhibitory phosphorylation of the APC regulator Hctl is controlled by the kinase Cdc28 and the phosphatase Cdc14. Curr. Biol. 9: $227-236$

Jensen, S., Segal, M., Clarke, D.J., and Reed, S.I. 2001. A novel role of the budding yeast separin Esp1 in anaphase spindle elongation: Evidence that proper spindle association of Esp1 is regulated by Pds1. J. Cell Biol. 152: 27-40.

Jin, D.Y., Spencer, F., and Jeang, K.T. 1998. Human T cell Leukemia virus type 1 oncoprotein Tax targets the human mitotic checkpoint protein MAD1. Cell 93: 81-91.

Jorgensen, P.M., Brundell, E., Starborg, M., and Hoog, C. 1998. A subunit of the anaphase-promoting complex is a centromereassociated protein in mammalian cells. Mol. Cell. Biol. 18: $468-476$.

Juang, Y.L., Huang, J., Peters, J.M., McLaughlin, M.E., Tai, C.Y., and Pellman, D. 1997. APC-mediated proteolysis of Ase1 and the morphogenesis of the mitotic spindle. Science 275: $1311-1314$.

Kaiser, B.K., Zimmerman, Z.A., Charbonneau, H., and Jackson, P.K. 2002. Disruption of centrosome structure, chromosome segregation, and cytokinesis by misexpression of human Cdc14A phosphatase. Mol. Biol. Cell 13: 2289-2300.

Kallio, M., Weinstein, J., Daum, J.R., Burke, D.J., and Gorbsky, G.J. 1998. Mammalian p55 ${ }^{\mathrm{CDC}}$ mediates association of the spindle checkpoint protein Mad2 with the cyclosome/anaphase-promoting complex, and is involved in regulating anaphase onset and late mitotic events. J. Cell Biol. 141: 13931406.

Kamura, T., Koepp, D.M., Conrad, M.N., Skowyra, D., Moreland, R.J., Iliopoulos, O., Lane, W.S., Kaelin, W.G., Jr., Elledge, S.J., Conaway, R.C., et al. 1999. Rbx1, a component of the VHL tumor suppressor complex and SCF ubiquitin ligase. Science 284: 657-661.

Kim, S.H., Lin, D.P., Matsumoto, S., Kitazono, A., and Matsumoto, T. 1998. Fission yeast Slp1: An effector of the Mad2dependent spindle checkpoint. Science 279: 1045-1047. 
King, R.W., Peters, J.M., Tugendreich, S., Rolfe, M., Hieter, P., and Kirschner, M.W. 1995. A 20S complex containing CDC27 and CDC16 catalyzes the mitosis-specific conjugation of ubiquitin to cyclin B. Cell 81: 279-288.

King, R.W., Glotzer, M., and Kirschner, M.W. 1996. Mutagenic analysis of the destruction signal of mitotic cyclins and structural characterization of ubiquitinated intermediates. Mol. Biol. Cell 7: 1343-1357.

Klotzbucher, A., Stewart, E., Harrison, D., and Hunt, T. 1996. The 'destruction box' of cyclin A allows B-type cyclins to be ubiquitinated, but not efficiently destroyed. EMBO $J$. 15: 3053-3064

Knoblich, J.A. 2001. Asymmetric cell division during animal development. Nat. Rev. Mol. Cell Biol. 2: 11-20.

Koepp, D.M., Harper, J.W., and Elledge, S.J. 1999. How the cyclin became a cyclin: Regulated proteolysis in the cell cycle. Cell 97: 431-434.

Kominami, K., Seth-Smith, H., and Toda, T. 1998. Apc10 and Ste9/Srw1, two regulators of the APC-cyclosome, as well as the CDK inhibitor Rum 1 are required for $\mathrm{G}_{1}$ cell-cycle arrest in fission yeast. EMBO J. 17: 5388-5399.

Kotani, S., Tugendreich, S., Fujii, M., Jorgensen, P.M., Watanabe, N., Hoog, C., Hieter, P., and Todokoro, K. 1998. PKA and MPF-activated Polo-like kinase regulate anaphase-promoting complex activity and mitosis progression. Mol. Cell 1: $371-380$

Kotani, S., Tanaka, H., Yasuda, H., and Todokoro, K. 1999. Regulation of APC activity by phosphorylation and regulatory factors. J. Cell Biol. 146: 791-800.

Kramer, E.R., Gieffers, C., Holzl, G., Hengstschlager, M., and Peters, J.M. 1998. Activation of the human anaphase-promoting complex by proteins of the CDC20/Fizzy family. Curr. Biol. 8: 1207-1210.

Kramer, E.R., Scheuringer, N., Podtelejnikov, A.V., Mann, M., and Peters, J.M. 2000. Mitotic regulation of the APC activator proteins CDC20 and CDH1. Mol. Biol. Cell 11: 15551569.

Kramer, K.M., Fesquet, D., Johnson, A.L., and Johnston, L.H. 1998. Budding yeast RSI1/APC2, a novel gene necessary for initiation of anaphase, encodes an APC subunit. EMBO J. 17: 498-506.

Kumada, K., Nakamura, T., Nagao, K., Funabiki, H., Nakagawa, T., and Yanagida, M. 1998. Cut1 is loaded onto the spindle by binding to Cut 2 and promotes anaphase spindle movement upon Cut2 proteolysis. Curr. Biol. 8: 633-641.

Kurasawa, Y. and Todokoro, K. 1999. Identification of human APC10/Doc1 as a subunit of anaphase promoting complex. Oncogene 18: 5131-5137.

Kurz, T., Pintard, L., Willis, J.H., Hamill, D.R., Gonczy, P., Peter, M., and Bowerman, B. 2002. Cytoskeletal regulation by the Nedd8 ubiquitin-like protein modification pathway. Science 295: 1294-1298.

Lahav-Baratz, S., Sudakin, V., Ruderman, J.V., and Hershko, A. 1995. Reversible phosphorylation controls the activity of cyclosome-associated cyclin-ubiquitin ligase. Proc. Natl. Acad. Sci. 92: 9303-9307.

Lanker, S., Valdivieso, M.H., and Wittenberg, C. 1996. Rapid degradation of the $\mathrm{G}_{1}$ cyclin $\mathrm{Cln} 2$ induced by CDK-dependent phosphorylation. Science 271: 1597-1601.

Leverson, J.D., Joazeiro, C.A., Page, A.M., Huang, H., Hieter, P., and Hunter, T. 2000. The APC11 RING-H2 finger mediates E2-dependent ubiquitination. Mol. Biol. Cell 11: 2315-2325.

Li, R. 1999. Bifurcation of the mitotic checkpoint pathway in budding yeast. Proc. Natl. Acad. Sci. 96: 4989-4994.

Li, R. and Murray, A.W. 1991. Feedback control of mitosis in budding yeast. Cell 66: 519-531.
Li, Y. and Benezra, R. 1996. Identification of a human mitotic checkpoint gene: hsMAD2. Science 274: 246-248.

Li, Y., Gorbea, C., Mahaffey, D., Rechsteiner, M., and Benezra, R. 1997. MAD2 associates with the cyclosome/anaphasepromoting complex and inhibits its activity. Proc. Natl. Acad. Sci. 94: 12431-12436.

Lim, H.H., Goh, P.Y., and Surana, U. 1998. Cdc20 is essential for the cyclosome-mediated proteolysis of both Pds1 and Clb2 during $\mathrm{M}$ phase in budding yeast. Curr. Biol. 8: 231234.

Listovsky, T., Zor, A., Laronne, A., and Brandeis, M. 2000. Cdk1 is essential for mammalian cyclosome/APC regulation. Exp. Cell. Res. 255: 184-191.

Littlepage, L.E. and Ruderman, J.V. 2002. Identification of a new $\mathrm{APC} / \mathrm{C}$ recognition domain, the $\mathrm{A}$ box, which is required for the Cdh1-dependent destruction of the kinase Aurora-A during mitotic exit. Genes \& Dev. (this issue).

Lorca, T., Castro, A., Martinez, A.M., Vigneron, S., Morin, N., Sigrist, S., Lehner, C., Dorée, M., and Labbé, J.C. 1998. Fizzy is required for activation of the APC/cyclosome in Xenopus egg extracts. $E M B O J$. 17: 3565-3575.

Luca, F.C. and Ruderman, J.V. 1989. Control of programmed cyclin destruction in a cell free system. J. Cell Biol. 109: 1895-1909.

Lukas, C., Sorensen, C.S., Kramer, E., Santoni-Rugiu, E., Lindeneg, C., Peters, J.M., Bartek, J., and Lukas, J. 1999. Accumulation of cyclin B1 requires E2F and cyclin-A-dependent rearrangement of the anaphase-promoting complex. Nature 401: 815-818.

Luo, X., Fang, G., Coldiron, M., Lin, Y., Yu, H., Kirschner, M.W., and Wagner, G. 2000. Structure of the Mad2 spindle assembly checkpoint protein and its interaction with Cdc20. Nat. Struct. Biol. 7: 224-229.

Luo, X., Tang, Z., Rizo, J., and Yu, H. 2002. The Mad2 spindle checkpoint protein undergoes similar major conformational changes upon binding to either Mad1 or Cdc20. Mol. Cell 9: $59-71$.

Lygerou, Z. and Nurse, P. 2000. Cell cycle. License withheldGeminin blocks DNA replication. Science 290: 2271-2273.

Mailand, N., Lukas, C., Kaiser, B.K., Jackson, P.K., Bartek, J., and Lukas, J. 2002. Deregulated human Cdc14A phosphatase disrupts centrosome separation and chromosome segregation. Nat. Cell Biol. 4: 318-322.

Mathias, N., Johnson, S.L., Winey, M., Adams, A.E., Goetsch, L., Pringle, J.R., Byers, B., and Goebl, M.G. 1996. Cdc53p acts in concert with $\mathrm{Cdc} 4 \mathrm{p}$ and $\mathrm{Cdc} 34 \mathrm{p}$ to control the $\mathrm{G}_{1}$-to-S phase transition and identifies a conserved family of proteins. Mol. Cell. Biol. 16: 6634-6643.

May, K.M., Reynolds, N., Cullen, C.F., Yanagida, M., and Ohkura, H. 2002. Polo boxes and Cut23 (Apc8) mediate an interaction between Polo kinase and the anaphase-promoting complex for fission yeast mitosis. J. Cell Biol. 156: 23-28.

McCollum, D. and Gould, K.L. 2001. Timing is everything: Regulation of mitotic exit and cytokinesis by the MEN and SIN. Trends Cell Biol. 11: 89-95.

McGarry, T.J. and Kirschner, M.W. 1998. Geminin, an inhibitor of DNA replication, is degraded during mitosis. Cell 93: 1043-1053.

Meraldi, P., Honda, R., and Nigg, E.A. 2002. Aurora-A overexpression reveals tetraploidization as a major route to centrosome amplification in p53 $3^{-/-}$cells. EMBO J. 21: $483-$ 492.

Michaelis, C., Ciosk, R., and Nasmyth, K. 1997. Cohesins: Chromosomal proteins that prevent premature separation of sister chromatids. Cell 91: 35-45. 
Michel, L.S., Liberal, V., Chatterjee, A., Kirchwegger, R., Pasche, B., Gerald, W., Dobles, M., Sorger, P.K., Murty, V.V., and Benezra, R. 2001. MAD2 haplo-insufficiency causes premature anaphase and chromosome instability in mammalian cells. Nature 409: 355-359.

Millband, D.N. and Hardwick, K.G. 2002. Fission yeast Mad3p is required for Mad2p to inhibit the anaphase-promoting complex and localizes to kinetochores in a Bublp-, Bub3p-, and Mphlp-dependent manner. Mol. Cell. Biol. 22: 27282742.

Morgan, D.O. 1999. Regulation of the APC and the exit from mitosis. Nat. Cell Biol. 1: E47-E53.

Murray, A.W. and Kirschner, M.W. 1989. Cyclin synthesis drives the early embryonic cell cycle. Nature 339: 275-280.

Murray, A.W., Solomon, M.J., and Kirschner, M.W. 1989. The role of cyclin synthesis and degradation in the control of maturating promoting factor activity. Nature 339: 280 286.

Nash P., Tang, X., Orlicky, S., Chen, Q., Gertler, F.B., Mendenhall, M.D., Sicheri, F., Pawson, T., and Tyers, M. 2001. Multisite phosphorylation of a CDK inhibitor sets a threshold for the onset of DNA replication. Nature 414: 514-521.

Nasmyth, K. 1999. Separating sister chromatids. Trends Biochem. Sci. 24: 98-104.

Nasmyth, K., Peters, J.M., and Uhlmann, F. 2000. Splitting the chromosome: Cutting the ties that bind sister chromatids. Science 288: 1379-1385.

Nishitani, H., Taraviras, S., Lygerou, Z., and Nishimoto, T. 2001. The human licensing factor for DNA replication Cdt1 accumulates in $G_{1}$ and is destabilized after initiation of $S$ phase. J. Biol. Chem. 276: 44905-44911.

Noton, E. and Diffley, J.F. 2000. CDK inactivation is the only essential function of the APC/C and the mitotic exit network proteins for origin resetting during mitosis. Mol. Cell 5: 85-95.

Ohta, T., Michel, J.J., Schottelius, A.J., and Xiong, Y. 1999. ROC1, a homolog of APC11, represents a family of cullin partners with an associated ubiquitin ligase activity. Mol. Cell 3: 535-541.

Ohtoshi, A., Maeda, T., Higashi, H., Ashizawa, S., and Hatakeyama, M. 2000. Human p55/Cdc20 associates with cyclin A and is phosphorylated by the cyclin A-Cdk2 complex. Biochem. Biophys. Res. Comm. 268: 530-534.

Oliferenko, S. and Balasubramanian, M.K. 2001. Cell cycle: The Flp side of Cdc14. Curr. Biol. 11: R872-R874.

Osaka, F., Seino, H., Seno, T., and Yamao, F. 1997. A ubiquitinconjugating enzyme in fission yeast that is essential for the onset of anaphase in mitosis. Mol. Cell. Biol. 17: 33883397.

Oshiro, G., Owens, J.C., Shellman, Y., Sclafani, R.A., and Li, J.J. 1999. Cell cycle control of Cdc7p kinase activity through regulation of Dbf4p stability. Mol. Cell. Biol. 19: 4888-4896.

Patra, D. and Dunphy, W.G. 1998. Xe-p9, a Xenopus Suc1/Cks protein, is essential for the Cdc2-dependent phosphorylation of the anaphase-promoting complex at mitosis. Genes \& Dev. 12: 2549-2559.

Patton, E.E., Willems, A.R., and Tyers, M. 1998. Combinatorial control in ubiquitin-dependent proteolysis: Don't Skp the F-box hypothesis. Trends Genet. 14: 236-243.

Pereira, G. and Schiebel, E. 2001. The role of the yeast spindle pole body and the mammalian centrosome in regulating late mitotic events. Curr. Opin. Cell Biol. 13: 762-769.

Pereira, G., Hofken, T., Grindlay, J., Manson, C., and Schiebel, E. 2000. The Bub2p spindle checkpoint links nuclear migration with mitotic exit. Mol. Cell 6: 1-10.

Perkins, G., Drury, L.S., and Diffley, J.F. 2001. Separate
$\mathrm{SCF}^{\mathrm{CDC} 4}$ recognition elements target $\mathrm{Cdc} 6$ for proteolysis in S phase and mitosis. EMBO J. 20: 4836-4845.

Peters, J.M., King, R.W., Hoog, C., and Kirschner, M.W. 1996. Identification of BIME as a subunit of the anaphase-promoting complex. Science 274: 1199-1201.

Petersen, B.O., Wagener, C., Marinoni, F., Kramer, E.R., Melixetian, M., Denchi, E.L., Gieffers, C., Matteucci, C., Peters, J.M., and Helin, K. 2000. Cell cycle- and cell growth-regulated proteolysis of mammalian CDC6 is dependent on APCCDH1. Genes \& Dev. 14: 2330-2343.

Pfleger, C.M. and Kirschner, M.W. 2000. The KEN box: An APC recognition signal distinct from the D box targeted by Cdh1. Genes \& Dev. 14: 655-665.

Pfleger, C.M., Lee, E., and Kirschner, M.W. 2001a. Substrate recognition by the Cdc20 and Cdh1 components of the anaphase-promoting complex. Genes \& Dev. 15: 2396-2407.

Pfleger, C.M., Salic, A., Lee, E., and Kirschner, M.W. 2001b. Inhibition of Cdh1-APC by the MAD2-related protein MAD2L2: A novel mechanism for regulating Cdh1. Genes \& Dev. 15: 1759-1764.

Piatti, S., Bohm, T., Cocker, J.H., Diffley, J.F., and Nasmyth, K. 1996. Activation of S-phase-promoting CDKs in late $\mathrm{G}_{1}$ defines a "point of no return" after which Cdc6 synthesis cannot promote DNA replication in yeast. Genes \& Dev. 10: $1516-1531$

Pravtcheva, D.D. and Wise, T.L. 2001. Disruption of Apc10/ Doc1 in three alleles of oligosyndactylism. Genomics 72: $78-87$.

Prinz, S., Hwang, E.S., Visintin, R., and Amon, A. 1998. The regulation of Cdc20 proteolysis reveals a role for APC components $\mathrm{Cdc} 23$ and $\mathrm{Cdc} 27$ during $\mathrm{S}$ phase and early mitosis. Curr. Biol. 8: 750-760.

Rao, P.N. and Johnson, R.T. 1970. Mammalian cell fusion: Studies on the regulation of DNA synthesis and mitosis. Nature 225: $159-164$.

Rappleye, C.A., Tagawa, A., Lyczak, R., Bowerman, B., and Aroian, R.V. 2002. The anaphase-promoting complex and separin are required for embryonic anterior-posterior axis formation. Dev. Cell 2: 195-206.

Reimann, J.D. and Jackson, P.K. 2002. Emil is required for cytostatic factor arrest in vertebrate eggs. Nature 416: 850 854.

Reimann, J.D., Freed, E., Hsu, J.Y., Kramer, E.R., Peters, J.M., and Jackson, P.K. 2001a. Emil is a mitotic regulator that interacts with Cdc20 and inhibits the anaphase promoting complex. Cell 105: 645-655.

Reimann, J.D., Gardner, B.E., Margottin-Goguet, F., and Jackson, P.K. 2001b. Emil regulates the anaphase-promoting complex by a different mechanism than Mad2 proteins. Genes \& Dev. 15: 3278-3285.

Rudner, A.D. and Murray, A.W. 2000. Phosphorylation by Cdc28 activates the Cdc20-dependent activity of the anaphase-promoting complex. J. Cell Biol. 149: 1377-1390.

Rudner, A.D., Hardwick, K.G., and Murray, A.W. 2000. Cdc28 activates exit from mitosis in budding yeast. J. Cell Biol. 149: 1361-1376.

Salah, S.M. and Nasmyth, K. 2000. Destruction of the securin Pds1p occurs at the onset of anaphase during both meiotic divisions in yeast. Chromosoma 109: 27-34.

Schaar, B.T., Chan, G.K., Maddox, P., Salmon, E.D., and Yen, T.J. 1997. CENP-E function at kinetochores is essential for chromosome alignment. J. Cell Biol. 139: 1373-1382.

Schott, E.J. and Hoyt, M.A. 1998. Dominant alleles of Saccharomyces cerevisiae CDC20 reveal its role in promoting anaphase. Genetics 148: 599-610.

Schwab, M., Lutum, A.S., and Seufert, W. 1997. Yeast Hct1 is a 
regulator of Clb2 cyclin proteolysis. Cell 90: 683-693.

Schwab, M., Neutzner, M., Mocker, D., and Seufert, W. 2001. Yeast Hct1 recognizes the mitotic cyclin Clb2 and other substrates of the ubiquitin ligase APC. EMBO J. 20: 51655175.

Schwob, E., Bohm, T., Mendenhall, M.D., and Nasmyth, K. 1994. The B-type cyclin kinase inhibitor $\mathrm{p} 40^{\mathrm{SIC1}}$ controls the $\mathrm{G}_{1}$ to $\mathrm{S}$ transition in S. cerevisiae. Cell 79: 233-244.

Seol, J.H., Feldman, R.M., Zachariae, W., Shevchenko, A., Correll, C.C., Lyapina, S., Chi, Y., Galova, M., Claypool, J., Sandmeyer, S., et al. 1999. Cdc53/cullin and the essential hrt1 RING-H2 subunit of SCF define a ubiquitin ligase module that activates the E2 enzyme cdc34. Genes \& Dev. 13: 16141626.

Shirayama, M., Zachariae, W., Ciosk, R., and Nasmyth, K. 1998. The Polo-like kinase Cdc5p and the WD-repeat protein $\mathrm{Cdc} 20 \mathrm{p} /$ fizzy are regulators and substrates of the anaphase promoting complex in Saccharomyces cerevisiae. EMBO I. 17: 1336-1349.

Shirayama, M., Toth, A., Galova, M., and Nasmyth, K. 1999. $\mathrm{APC}^{\mathrm{Cdc20}}$ promotes exit from mitosis by destroying the anaphase inhibitor Pds1 and cyclin Clb5. Nature 402: 203-207.

Shou, W., Seol, J.H., Shevchenko, A., Baskerville, C., Moazed, D., Chen, Z.W., Jang, J., Charbonneau, H., and Deshaies, R.J. 1999. Exit from mitosis is triggered by Tem1-dependent release of the protein phosphatase Cdc14 from nucleolar RENT complex. Cell 97: 233-244.

Shteinberg, M., Protopopov, Y., Listovsky, T., Brandeis, M., and Hershko, A. 1999. Phosphorylation of the cyclosome is required for its stimulation by Fizzy/cdc20. Biochem. Biophys. Res. Commun. 260: 193-198.

Sigrist, S.J. and Lehner, C.F. 1997. Drosophila fizzy-related down-regulates mitotic cyclins and is required for cell proliferation arrest and entry into endocycles. Cell 90: 671-681.

Sigrist, S., Jacobs, H., Stratmann, R., and Lehner, C.F. 1995. Exit from mitosis is regulated by Drosophila fizzy and the sequential destruction of cyclins $\mathrm{A}, \mathrm{B}$ and $\mathrm{B} 3 . \mathrm{EMBO} \mathrm{T}$. 14: 4827-4838.

Sironi, L., Melixetian, M., Faretta, M., Prosperini, E., Helin, K., and Musacchio, A. 2001. Mad2 binding to Mad1 and Cdc20, rather than oligomerization, is required for the spindle checkpoint. EMBO J. 20: 6371-6382.

Sironi, L., Mapelli, M., Knapp, S., Antoni, A.D., Jeang, K.T., and Musacchio, A. 2002. Crystal structure of the tetrameric Mad1-Mad2 core complex: Implications of a 'safety belt' binding mechanism for the spindle checkpoint. EMBO $\mathrm{J}$. 21: 2496-2506

Skowyra, D., Craig, K., Tyers, M., Elledge, S.J., and Harper, J.W. 1997. F-box proteins are components of E3 complexes and act as receptors to recruit phosphorylated substrates for ubiquitination. Cell 91: 209-219.

Skowyra, D., Koepp, D.M., Kamura, T., Conrad, M.N., Conaway, R.C., Conaway, J.W., Elledge, S.J., and Harper, J.W. 1999. Reconstitution of $G_{1}$ cyclin ubiquitination with complexes containing $\mathrm{SCF}^{\mathrm{Grrl}}$ and Rbx1. Science 284: 662-665.

Sorensen, C.S., Lukas, C., Kramer, E.R., Peters, J.M., Bartek, J., and Lukas, J. 2000. Nonperiodic activity of the human anaphase-promoting complex-Cdh1 ubiquitin ligase results in continuous DNA synthesis uncoupled from mitosis. Mol. Cell. Biol. 20: 7613-7623.

- 2001. A conserved cyclin-binding domain determines functional interplay between anaphase-promoting complexCdh1 and cyclin A-Cdk2 during cell cycle progression. Mol. Cell. Biol. 21: 3692-3703.

Stegmeier, F., Visintin, R., and Amon, A. 2002. Separase, Polo kinase, the kinetochore protein S1k19, and Spo12 function in a network that controls Cdc14 localization during early anaphase. Cell 108: 207-220.

Stemmann, O., Zou, H., Gerber, S.A., Gygi, S.P., and Kirschner, M.W. 2001. Dual inhibition of sister chromatid separation at metaphase. Cell 107: 715-726.

Straight, A.F., Shou, W., Dowd, G.J., Turck, C.W., Deshaies, R.J., Johnson, A.D., and Moazed, D. 1999. Net1, a Sir2-associated nucleolar protein required for rDNA silencing and nucleolar integrity. Cell 97: 245-256.

Stroschein, S.L., Bonni, S., Wrana, J.L., and Luo, K. 2001. Smad3 recruits the anaphase-promoting complex for ubiquitination and degradation of SnoN. Genes \& Dev. 15: 2822-2836.

Sudakin, V., Ganoth, D., Dahan, A., Heller, H., Hershko, J., Luca, F.C., Ruderman, J.V., and Hershko, A. 1995. The cyclosome, a large complex containing cyclin-selective ubiquitin ligase activity. Mol. Biol. Cell 6: 185-197.

Sudakin, V., Chan, G.K., and Yen, T.J. 2001. Checkpoint inhibition of the APC/C in HeLa cells is mediated by a complex of BUBR1, BUB3, CDC20, and MAD2. J. Cell Biol. 154: 925-936.

Sudo, T., Ota, Y., Kotani, S., Nakao, M., Takami, Y., Takeda, S., and Saya, H. 2001. Activation of Cdh1-dependent APC is required for $\mathrm{G}_{1}$ cell cycle arrest and DNA damage-induced $\mathrm{G}_{2}$ checkpoint in vertebrate cells. EMBO J. 20: 6499-6508.

Sumara, I., Vorlaufer, E., Stukenberg, P.T., Kelm, O., Redemann, N., Nigg, E.A., and Peters, J.M. 2002. The dissociation of cohesin from chromosomes in prophase is regulated by Polo-like kinase. Mol. Cell 9: 515-525.

Taguchi, S., Honda, K., Sugiura, K., Yamaguchi, A., Furukaw, K., and Urano, T. 2002. Degradation of human aurora-A protein kinase is mediated by hCdh1. FEBS Lett. 519: 59-65.

Tanaka, K., Suzuki, T., and Chiba, T. 1998. The ligation systems for ubiquitin and ubiquitin-like proteins. Mol. Cell 8: $503-512$.

Tanaka, T., Cosma, M.P., Wirth, K., and Nasmyth, K. 1999. Identification of cohesin association sites at centromeres and along chromosome arms. Cell 98: 847-858.

Tang, Z., Li, B., Bharadwaj, R., Zhu, H., Ozkan, E., Hakala, K., Deisenhofer, J., and $\mathrm{Yu}, \mathrm{H}$. 2001a. APC2 cullin protein and APC11 RING protein comprise the minimal ubiquitin ligase module of the anaphase-promoting complex. Mol. Biol. Cell 12: 3839-3851.

Tang, Z., Bharadwaj, R., Li, B., and Yu, H. 2001b. Mad2-independent inhibition of $\mathrm{APC}^{\mathrm{Cdc} 20}$ by the mitotic checkpoint protein BubR1. Dev. Cell 1: 227-237.

Tatebe, H. and Yanagida, M. 2000. Cut8, essential for anaphase, controls localization of $26 \mathrm{~S}$ proteasome, facilitating destruction of cyclin and Cut2. Curr. Biol. 10: 1329-1338.

Taylor, S.S. and McKeon, F. 1997. Kinetochore localization of murine Bub1 is required for normal mitotic timing and checkpoint response to spindle damage. Cell 89: 727-735.

Taylor, S.S., Ha, E., and McKeon, F. 1998. The human homologue of Bub3 is required for kinetochore localization of Bub1 and a Mad3/Bub1-related protein kinase. J. Cell Biol. 142: $1-11$.

Tinker-Kulberg, R.L. and Morgan, D.O. 1999. Pds1 and Esp1 control both anaphase and mitotic exit in normal cells and after DNA damage. Genes \& Dev. 13: 1936-1949.

Tomonaga, T., Nagao, K., Kawasaki, Y., Furuya, K., Murakami, A., Morishita, J., Yuasa, T., Sutani, T., Kearsey, S.E., Uhlmann, F., et al. 2000. Characterization of fission yeast cohesin: Essential anaphase proteolysis of Rad21 phosphorylated in the S phase. Genes \& Dev. 14: 2757-2770.

Townsley, F.M., Aristarkhov, A., Beck, S., Hershko, A., and Ruderman, J.V. 1997. Dominant-negative cyclin-selective ubiquitin carrier protein $\mathrm{E} 2-\mathrm{C} / \mathrm{UbcH} 10$ blocks cells in metaphase. Proc. Nat1. Acad. Sci. 94: 2362-2367. 
Trautmann, S., Wolfe, B.A., Jorgensen, P., Tyers, M., Gould, K.L., and McCollum, D. 2001. Fission yeast Clp1p phosphatase regulates $G_{2} / M$ transition and coordination of cytokinesis with cell cycle progression. Curr. Biol. 11: 931-940.

Tyers, M. 1996. The cyclin-dependent kinase inhibitor p40SIC1 imposes the requirement for $\mathrm{Cln}_{1} \mathrm{G}_{1}$ cyclin function at Start. Proc. Natl. Acad. Sci. 93: 7772-7776.

Tyers, M., Tokiwa, G., Nash, R., and Futcher, B. 1992. The Cln3-Cdc28 kinase complex of $S$. cerevisiae is regulated by proteolysis and phosphorylation. EMBO J. 11: 1773-1784.

Uhlmann, F. and Nasmyth, K. 1998. Cohesion between sister chromatids must be established during DNA replication. Curr. Biol. 8: 1095-1101.

Uhlmann, F., Lottspeich, F., and Nasmyth, K. 1999. Sister-chromatid separation at anaphase onset is promoted by cleavage of the cohesin subunit Scc1. Nature 400: 37-42.

Uhlmann, F., Wernic, D., Poupart, M.A., Koonin, E.V., and Nasmyth, K. 2000. Cleavage of cohesin by the CD clan protease separin triggers anaphase in yeast. Cell 103: 375-386.

Verma, R., Annan, R.S., Huddleston, M.J., Carr, S.A., Reynard, G., and Deshaies, R.J. 1997. Phosphorylation of Siclp by $\mathrm{G}_{1}$ Cdk required for its degradation and entry into S-phase. Science 278: 455-460.

Visintin, R., Prinz, S., and Amon, A. 1997. CDC20 and CDH1: A family of substrate-specific activators of APC-dependent proteolysis. Science 278: 460-463.

Visintin, R., Craig, K., Hwang, E.S., Prinz, S., Tyers, M., and Amon, A. 1998. The phosphatase Cdc14 triggers mitotic exit by reversal of Cdk-dependent phosphorylation. Mol. Cell 2: 709-718.

Visintin, R., Hwang, E.S., and Amon, A. 1999. Cfil prevents premature exit from mitosis by anchoring Cdc14 phosphatase in the nucleolus. Nature 398: 818-823.

Waizenegger, I.C., Hauf, S., Meinke, A., and Peters, J.M. 2000. Two distinct pathways remove mammalian cohesin from chromosome arms in prophase and from centromeres in anaphase. Cell 103: 399-410.

Wan, Y. and Kirschner, M.W. 2001. Identification of multiple $\mathrm{CDH} 1$ homologues in vertebrates conferring different substrate specificities. Proc. Natl. Acad. Sci. 98: 13066-13071.

Wan, Y., Liu, X., and Kirschner, M.W. 2001. The anaphase-promoting complex mediates TGF- $\beta$ signaling by targeting SnoN for destruction. Mol. Cell 8: 1027-1039.

Wang, Y., Hu, F., and Elledge, S.J. 2000. The Bfa1/Bub2 GAP complex comprises a universal checkpoint required to prevent mitotic exit. Curr. Biol. 10: 1379-1382.

Wasch, R. and Cross, F.R. 2002. APC-dependent proteolysis of the mitotic cyclin $\mathrm{Clb} 2$ is essential for mitotic exit. Nature 418: $556-562$.

Wassmann, K. and Benezra, R. 1998. Mad2 transiently associates with an $\mathrm{APC} / \mathrm{p} 55^{\mathrm{Cdc}}$ complex during mitosis. Proc. Natl. Acad. Sci. 95: 11193-11198.

Weinstein, J. 1997. Cell cycle-regulated expression, phosphorylation, and degradation of $\mathrm{p} 55^{\mathrm{Cdc}}$. A mammalian homolog of CDC20/Fizzy/slp1. J. Biol. Chem. 272: 28501-28511.

Wendt, K.S., Vodermaier, H.C., Jacob, U., Gieffers, C., Gmachl, M., Peters, J.M., Huber, R., and Sondermann, P. 2001. Crystal structure of the APC10/DOC1 subunit of the human anaphase-promoting complex. Nat. Struct. Biol. 8: 784-788.

Willems, A.R., Lanker, S., Patton, E.E., Craig, K.L., Nason, T.F., Mathias, N., Kobayashi, R., Wittenberg, C., and Tyers, M. 1996. Cdc53 targets phosphorylated $G_{1}$ cyclins for degradation by the ubiquitin proteolytic pathway. Cell 86: 453-463.

Wirbelauer, C., Sutterluty, H., Blondel, M., Gstaiger, M., Peter, M., Reymond, F., and Krek, W. 2000. The F-box protein Skp2 is a ubiquitylation target of a Cull-based core ubiquitin li- gase complex: Evidence for a role of Cull in the suppression of $\mathrm{Skp} 2$ expression in quiescent fibroblasts. $E M B O J$. 19: 5362-5375.

Wohlschlegel, J.A., Dwyer, B.T., Dhar, S.K., Cvetic, C., Walter, J.C., and Dutta, A. 2000. Inhibition of eukaryotic DNA replication by geminin binding to Cdt1. Science 290: 2309-2312.

Wood, K.W., Sakowicz, R., Goldstein, L.S., and Cleveland, D.W 1997. CENP-E is a plus end-directed kinetochore motor required for metaphase chromosome alignment. Cell 91: 357366.

Wu, H., Lan, Z., Li, W., Wu, S., Weinstein, J., Sakamoto, K.M., and Dai, W. 2000. p55 $\mathrm{CDC} / \mathrm{hCDC} 20$ is associated with BUBR1 and may be a downstream target of the spindle checkpoint kinase. Oncogene 19: 4557-4562.

Yamada, H., Kumada, K., and Yanagida, M. 1997. Distinct subunit functions and cell cycle regulated phosphorylation of $20 \mathrm{~S}$ APC/cyclosome required for anaphase in fission yeast. $J$. Cell Sci. 110: 1793-1804.

Yamamoto, A., Guacci, V., and Koshland, D. 1996. Pds1p, an inhibitor of anaphase in budding yeast, plays a critical role in the APC and checkpoint pathway(s). J. Cell Biol. 133: 99110 .

Yamashita, Y.M., Nakaseko, Y., Samejima, I., Kumada, K., Yamada, H., Michaelson, D., and Yanagida, M. 1996. 20S cyclosome complex formation and proteolytic activity inhibited by the cAMP/PKA pathway. Nature 384: 276-279.

Yamashita, Y.M., Nakaseko, Y., Kumada, K., Nakagawa, T., and Yanagida, M. 1999. Fission yeast APC/cyclosome subunits, Cut20/Apc4 and Cut23/Apc8, in regulating metaphase-anaphase progression and cellular stress responses. Genes Cells 4: 445-463.

Yanagida, M. 2000. Cell cycle mechanisms of sister chromatid separation; roles of Cut $1 /$ separin and Cut $2 /$ securin. Genes Cells 5: 1-8.

Yao, X., Abrieu, A., Zheng, Y., Sullivan, K.F., and Cleveland, D.W. 2000. CENP-E forms a link between attachment of spindle microtubules to kinetochores and the mitotic checkpoint. Nat. Cell Biol. 2: 484-491.

Yeong, F.M., Lim, H.H., Padmashree, C.G., and Surana, U. 2000. Exit from mitosis in budding yeast: Biphasic inactivation of the Cdc28-Clb2 mitotic kinase and the role of Cdc20. Mol. Cell 5: 501-511.

Yeong, F.M., Lim, H.H., Wang, Y., and Surana, U. 2001. Early expressed $\mathrm{Clb}$ proteins allow accumulation of mitotic cyclin by inactivating proteolytic machinery during $\mathrm{S}$ phase. Mol. Cell. Biol. 21: 5071-5081.

Yu, H., King, R.W., Peters, J.M., and Kirschner, M.W. 1996. Identification of a novel ubiquitin-conjugating enzyme involved in mitotic cyclin degradation. Curr. Biol. 6: 455-466.

Yu, H., Peters, J.M., King, R.W., Page, A.M., Hieter, P., and Kirschner, M.W. 1998. Identification of a cullin homology region in a subunit of the anaphase-promoting complex. Science 279: 1219-1222.

Yudkovsky, Y., Shteinberg, M., Listovsky, T., Brandeis, M., and Hershko, A. 2000. Phosphorylation of Cdc20/fizzy negatively regulates the mammalian cyclosome/APC in the mitotic checkpoint. Biochem. Biophys. Res. Commun. 271: 299-304.

Zachariae, W. and Nasmyth, K. 1996. TPR proteins required for anaphase progression mediate ubiquitination of mitotic Btype cyclins in yeast. Mol. Biol. Cell 7: 791-801.

. 1999. Whose end is destruction: Cell division and the anaphase-promoting complex. Genes \& Dev. 13: 2039-2058.

Zachariae, W., Shin, T.H., Galova, M., Obermaier, B., and Nasmyth, K. 1996. Identification of subunits of the anaphase- 
Harper et al.

promoting complex of Saccharomyces cerevisiae. Science 274: 1201-1204.

Zachariae, W., Schwab, M., Nasmyth, K., and Seufert, W. 1998a. Control of cyclin ubiquitination by CDK-regulated binding of Hctl to the anaphase promoting complex. Science 282: 1721-1724.

Zachariae, W., Shevchenko, A., Andrews, P.D., Ciosk, R., Galova, M., Stark, M.J., Mann, M., and Nasmyth, K. 1998b. Mass spectrometric analysis of the anaphase-promoting complex from yeast: Identification of a subunit related to cullins. Science 279: 1216-1219.

Zheng, N., Wang, P., Jeffrey, P.D., and Pavletich, N.P. 2000. Structure of a c-Cbl-UbcH7 complex: RING domain function in ubiquitin-protein ligases. Cell 102: 533-539.

Zheng, N., Schulman, B.A., Song, L., Miller, J.J., Jeffrey, P.D., Wang, P., Chu, C., Koepp, D.M., Elledge, S.J., Pagano, M., et al. 2002. Structure of the Cul1-Rbx1-Skp1-F box ${ }^{\text {Skp2 }}$ SCF ubiquitin ligase complex. Nature 416: 703-709.

Zou, H., McGarry, T.J., Bernal, T., and Kirschner, M.W. 1999. Identification of a vertebrate sister-chromatid separation inhibitor involved in transformation and tumorigenesis. Science 285: 418-422.

Zur, A. and Brandeis, M. 2001. Securin degradation is mediated by fzy and fzr, and is required for complete chromatid separation but not for cytokinesis. EMBO J. 20: 792-801. 


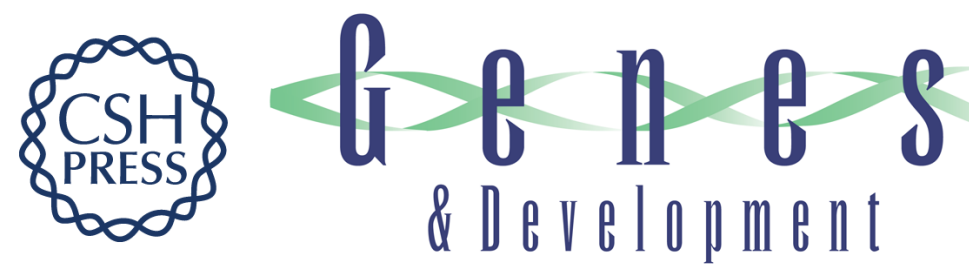

\section{The anaphase-promoting complex: it's not just for mitosis any more}

J. Wade Harper, Janet L. Burton and Mark J. Solomon

Genes Dev. 2002, 16:

Access the most recent version at doi:10.1101/gad.1013102

References This article cites 256 articles, 135 of which can be accessed free at: http://genesdev.cshlp.org/content/16/17/2179.full.html\#ref-list-1

License

Email Alerting Receive free email alerts when new articles cite this article - sign up in the box at the top right Service corner of the article or click here.

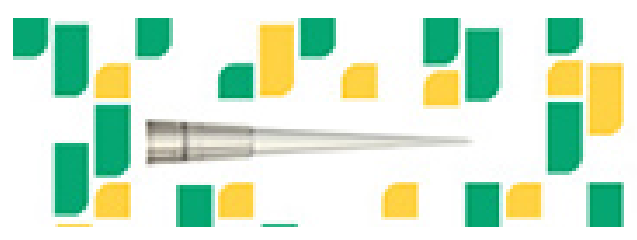

Focused on your science.

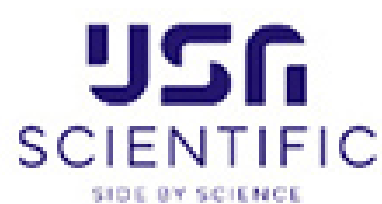

